\title{
Inhibition of ADAM17 impairs endothelial cell necroptosis and blocks metastasis
}

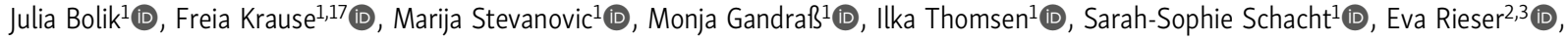

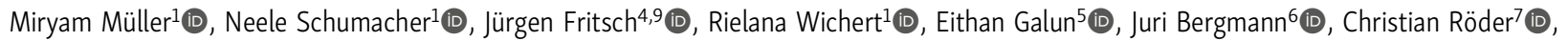 \\ Clemens Schafmayer ${ }^{8} \mathbb{D}$, Jan-Hendrik Egberts ${ }^{8} \mathbb{D}$, Christoph Becker-Pauly ${ }^{1} \mathbb{D}$, Paul Saftig ${ }^{1} \mathbb{D}$, Ralph Lucius ${ }^{6}$ (D), Wulf Schneider-Brachert ${ }^{9} \mathbb{E}^{\mathbb{D}}$,

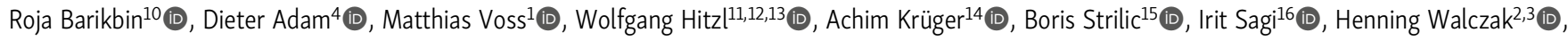 \\ Stefan Rose-John ${ }^{1}$ iD, and Dirk Schmidt-Arras ${ }^{1,17}$ (D)
}

\begin{abstract}
Metastasis is the major cause of death in cancer patients. Circulating tumor cells need to migrate through the endothelial layer of blood vessels to escape the hostile circulation and establish metastases at distant organ sites. Here, we identified the membrane-bound metalloprotease ADAM17 on endothelial cells as a key driver of metastasis. We show that TNFR1dependent tumor cell-induced endothelial cell death, tumor cell extravasation, and subsequent metastatic seeding is dependent on the activity of endothelial ADAM17. Moreover, we reveal that ADAM17-mediated TNFR1 ectodomain shedding and subsequent processing by the $y$-secretase complex is required for the induction of TNF-induced necroptosis. Consequently, genetic ablation of ADAM17 in endothelial cells as well as short-term pharmacological inhibition of ADAM17 prevents long-term metastases formation in the lung. Thus, our data identified ADAM17 as a novel essential regulator of necroptosis and as a new promising target for antimetastatic and advanced-stage cancer therapies.
\end{abstract}

\section{Introduction}

Tumor metastasis, a process where circulating tumor cells (CTCs) disseminate to distant organs, is a major cause of cancerrelated death. CTCs establish metastases after extravasation from blood (or lymph) vessels and subsequently invade the target tissue, thereby escaping immune surveillance mechanisms within the circulation. CTC extravasation involves adhesion to microvascular endothelium, elevation of endothelial permeability, and transendothelial migration into the underlying tissue. All steps during tumor cell (TC) extravasation can be induced either by paracrine factors secreted from the TCs or by interacting hematopoietic cells, such as macrophages, granulocytes, or platelets (Strilic and Offermanns, 2017). Several of these factors, such as C-C motif chemokine 2 (CCL2; Wolf et al., 2012) or ATP (Schumacher et al., 2013) signal via G protein- coupled receptors on either endothelial cells (ECs) or myeloid cells.

Release of TNF from macrophages promotes both hematogenic and lymphogenic tumor metastasis (Kim et al., 2009; Ji et al., 2014). TNF-induced engagement of TNF receptor 1 (TNFR1) results in intracellular formation of the membranebound complex I of TNFR1 signaling. Complex I is a large multiprotein complex that includes recruitment of the adaptor proteins TNFR1-associated with death domain (TRADD), TNFRassociated factor 2 , receptor interacting kinase 1 (RIPK1), and the E3 ubiquitin ligases cellular inhibitor of apoptosis proteins 1 and 2 (Brenner et al., 2015; Peltzer and Walczak, 2019). Ubiquitination of RIPK1 and other signal proteins of complex I is essential for the recruitment of kinase complexes, which finally results in

${ }^{1}$ Institute of Biochemistry, Christian-Albrechts-University Kiel, Kiel, Germany; ${ }^{2}$ Centre for Cell Death, Cancer and Inflammation, UCL Cancer Institute, University College London, London, United Kingdom; ${ }^{3}$ Institute for Biochemistry I, Medical Faculty, University of Cologne, Cologne, Germany; ${ }^{4}$ Institute of Immunology, Christian-AlbrechtsUniversity Kiel, Kiel, Germany; ${ }^{5}$ The Goldyne Savad Institute of Gene Therapy, Hadassah Hebrew University Hospital, Ein Karem, Jerusalem, Israel; ${ }^{6}$ Institute of Anatomy, Christian-Albrechts-University Kiel, Kiel, Germany; ${ }^{7}$ Institute for Experimental Cancer Research, University Medical Center Schleswig-Holstein, Kiel, Germany;

${ }^{8}$ Department of General Surgery and Thoracic Surgery, University Medical Center Schleswig-Holstein, Kiel, Germany; ${ }^{9}$ Department of Infection Prevention and Infectious Diseases, University Hospital Regensburg, Regensburg, Germany; ${ }^{10}$ Institute of Experimental Immunology and Hepatology, University Medical Center Hamburg-Eppendorf, Hamburg, Germany; ${ }^{11}$ Research Office (Biostatistics), Paracelsus Medical University, Salzburg, Austria; ${ }^{12}$ Research Program for Experimental Ophthalmology and Glaucoma, Paracelsus Medical University, Salzburg, Austria; ${ }^{13}$ Department of Ophthalmology and Optometry, Paracelsus Medical University Salzburg, Salzburg, Austria; ${ }^{14}$ Institutes for Molecular Immunology and Experimental Oncology, Technical University of Munich, Munich, Germany; ${ }^{15}$ Department of Pharmacology, Max-PlanckInstitute for Heart and Lung Research, Bad Nauheim, Germany; ${ }^{16}$ Department of Biological Regulation, Weizmann Institute of Science, Rehovot, Israel; ${ }^{17}$ Department of Biosciences, Paris-Lodron University Salzburg, Salzburg, Austria.

Correspondence to Dirk Schmidt-Arras: dirk.schmidt-arras@plus.ac.at; M. Müller's present address is the Beatson Institute for Cancer Research, Glasgow, United Kingdom.

(c) 2021 Bolik et al. This article is distributed under the terms of an Attribution-Noncommercial-Share Alike-No Mirror Sites license for the first six months after the publication date (see http://www.rupress.org/terms/). After six months it is available under a Creative Commons License (Attribution-Noncommercial-Share Alike 4.0 International license, as described at https://creativecommons.org/licenses/by-nc-sa/4.0/). 
phosphorylation of inhibitor of NF- $\kappa \mathrm{B}$ (IкB) and subsequent gene induction through nuclear translocation of NF- $\kappa$ B. Notably, complex I disassembly and RIPK1 deubiquitination induces a switch from TNFR1 prosurvival signaling to induction of cell death. This can either be mediated via formation of a cytosolic complex II resulting in pro-caspase-8 recruitment, activation, and execution of apoptosis or via formation of a heteroamyloid complex called necrosome. The necrosome consists of the adaptor protein Fas-associated with death domain (FADD) and RIPK1 and 3. The latter phosphorylates the pseudokinase mixedlineage kinase domain-like (MLKL), leading to the induction of cell death via MLKL-mediated pore formation and subsequent necrosis (Brenner et al., 2015; Peltzer and Walczak, 2019). By contrast, TNFR2 is lacking a death domain in its cytoplasmic domain and, therefore, is unable to directly induce cell death. TNFR2 engagement, rather, results in the activation of NF- $\mathrm{kB}$ signaling (Brenner et al., 2015). The affinity of TNFR2 for membrane-bound TNF was demonstrated to be higher than for soluble TNF (Grell et al., 1995). Interestingly, while TNFR1 is ubiquitously expressed, TNFR2 expression is restricted to hematopoietic and ECs (Brenner et al., 2015).

Induction of EC necroptosis and concomitant release of death-associated molecular patterns is discussed as a mechanism of how CTCs breach the endothelial barrier (Strilic et al., 2016; Hänggi et al., 2017; Hou et al., 2019; Yang et al., 2019; Patel et al., 2020). However, the detailed mechanism underlying endothelial barrier opening during TC extravasation is still incompletely understood. Identification of inducers and mediators of this process could potentially establish therapeutic targets against metastasis.

Proteolytic release of ectodomains, a process termed ectodomain shedding, is an irreversible posttranslational mechanism that regulates protein function, intracellular signaling, and provision of signals to neighboring cells. Members of the disintegrin and metalloprotease (ADAM) family are major mediators of ectodomain shedding (Reiss and Saftig, 2009). The family member ADAM17 is a membrane-bound metalloprotease involved in the shedding of a plethora of transmembrane proteins, including growth factors, cytokines, and receptor molecules (Reiss and Saftig, 2009).

Activation of ADAM17 has been linked to the engagement of $\mathrm{G}$ protein-coupled receptors, as well as to $\mathrm{p} 38$ and ERK MAPKs (Xu et al., 2012). Mice with genetic deficiency in Adaml7 are embryonically lethal (Peschon et al., 1998). In addition, ADAM17inactivating mutations are associated with severe pathologies in humans (Blaydon et al., 2011), mainly caused by impaired release of epidermal growth factor receptor (EGFR) ligands. We previously generated viable ADAM17 hypomorphic (ADAM17ex/ex) mice exhibiting only $\sim 5 \%$ residual Adaml7 expression in all tissues, allowing us to study the impact of ADAM17 deficiency in vivo (Chalaris et al., 2010). ADAM17 is involved in the generation of a chronic inflammatory state, thereby predisposing to cancer development, since it proteolytically cleaves and releases TNF and IL-6R (Scheller et al., 2011). Overexpression of ADAM17 in TCs of primary tumors (Murphy, 2008) is often observed and predominantly linked to autocrine EGFR activation on TCs. So far, the impact of ADAM17 on CTC extravasation and subsequent formation of metastases has not been addressed. Given that proteolytic release of TNF is predominantly mediated by ADAM17, we hypothesized that ADAM17 might be essentially involved in CTC extravasation and metastases formation through regulation of the TNF/TNFR signaling cascade.

In the present study, we discovered that proteolytic processing of TNFR1 by ADAM17 is essential for the induction of cellular necroptosis. We demonstrate that as such, ADAM17 is crucial for TC-induced EC death and acts as a facilitator of TC extravasation and metastases formation. Consequently, acute treatment of mice with the antagonistically acting recombinant prodomain (PD) of ADAM17 and thereby blocking ADAM17 catalytic activity was sufficient to prevent TC extravasation and formation of metastatic colonies in the long term. Therefore, ADAM17 is a novel and promising target for advanced-stage cancer therapy.

\section{Results}

\section{Microenvironmental ADAM17 promotes metastasis}

We employed a murine model of hematogenic metastasis in which syngeneic TCs were i.v. injected into immunocompetent mice, resulting in the formation of experimental lung metastases. To investigate the impact of microenvironmental ADAM17 on TC extravasation and metastatic colony formation, we used hypomorphic ADAM17ex/ex mice in which residual ADAM17 expression is lowered to $5 \%$ compared with WT control mice (Fig. $1 \mathrm{~A}$ and Fig. S1 A). We injected either Lewis lung carcinoma (LLC) or B16F1 melanoma TCs into both ADAM17ex/ex mice and WT animals (Fig. 1 B). While ADAM17 was markedly reduced in the metastatic microenvironment of ADAM17 ${ }^{\mathrm{ex} / \mathrm{ex}}$ mice, the inoculated TCs were still ADAM17 proficient (Fig. $1 \mathrm{~A}$ and Fig. S1 B). Using TCs with stable $\beta$-galactosidase ( $\beta$-Gal; LacZ) expression, we detected significantly reduced numbers of LLC TCs $6 \mathrm{~h}$ after injection in the lungs of ADAM17 ${ }^{\text {ex/ex }}$ mice compared with controls (Fig. 1 C), indicating reduced TC extravasation in these mice. The number of extravasated B16F1 TCs in ADAM17ex/ex mice was reduced to a similar extent (Fig. 1 D). Importantly, we also observed a striking effect on metastases formation, irrespective of the tumor entity, 3 wk after TC inoculation, where ADAM17 ${ }^{e x / e x}$ mice displayed a drastically decreased tumor burden (Fig. 1, E and F). Consequently, ADAM17-deficient mice were significantly protected from metastasis-induced death (Fig. $1 \mathrm{G}$ ).

\section{EC-derived ADAM17 promotes tumor extravasation and metastatic seeding}

We hypothesized a reduction in vascular leakage as the reason for the impaired TC extravasation in the absence of ADAM17. $6 \mathrm{~h}$ after TC injection, we observed a transient increase of vascular permeability in mice, as determined by FITC-dextran egress, which was significantly lower in ADAM17 ${ }^{\text {ex/ex }}$ mice than in WT control (Fig. 2, A and B) and declined to baseline levels after $24 \mathrm{~h}$ in both mouse variants (data not shown). We concluded that ECderived ADAM17 might control transendothelial migration of CTCs. In agreement with this assumption, we observed that migration of fluorescently labeled TCs through a monolayer of HUVECs and human lung microvascular ECs (HMVEC-L) was 


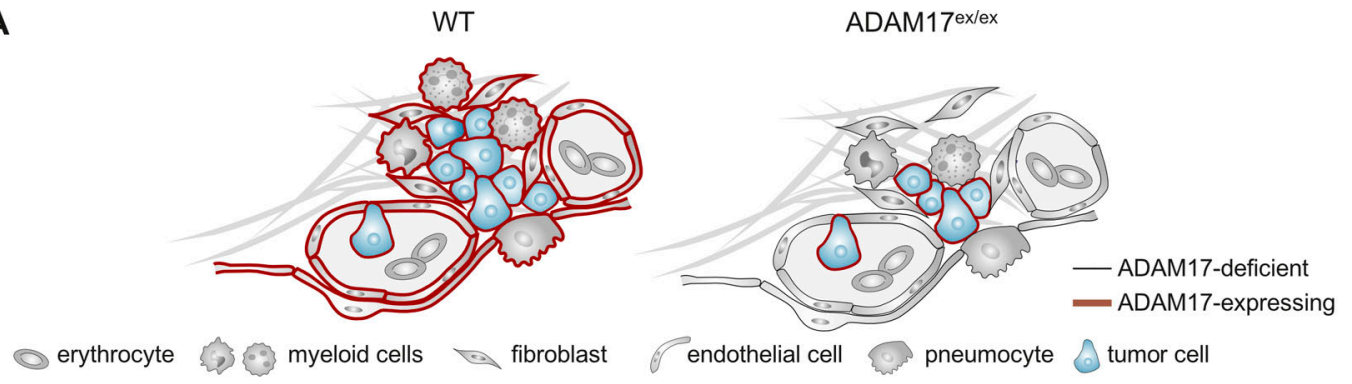

B syngeneic TCs:

LLC, LLC-LacZ,

v180. B16F1, B16F1-LacZ

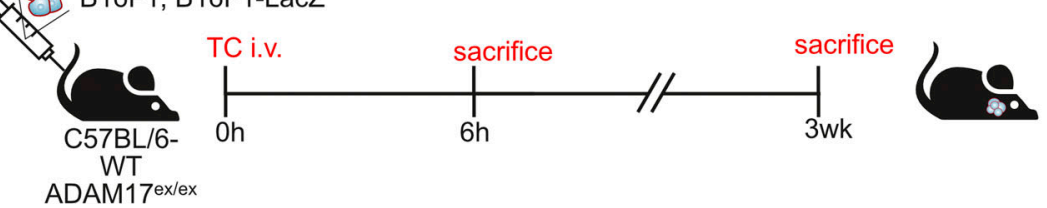

ADAM17ex/ex
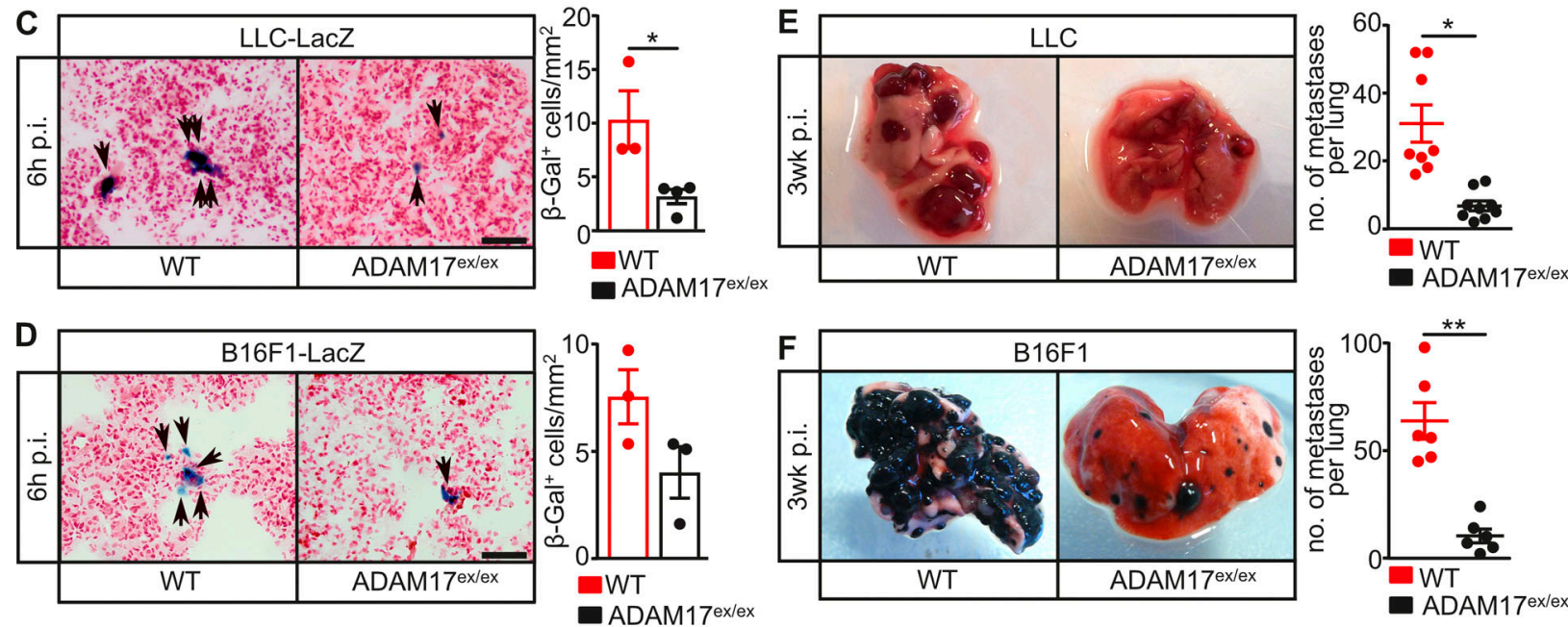

G

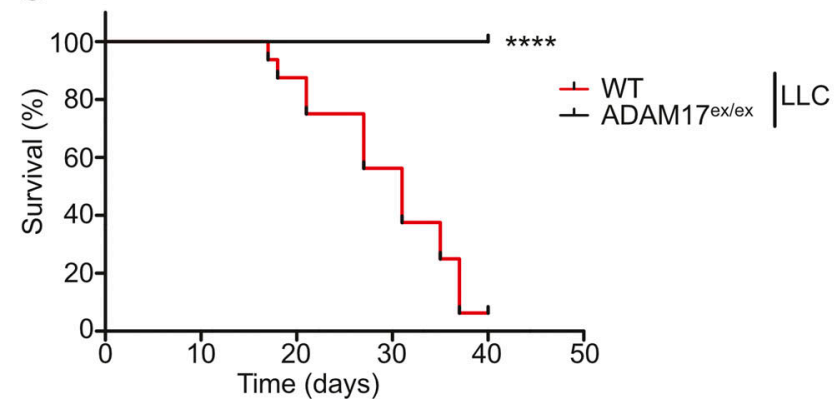

Figure 1. Host ADAM17 promotes metastasis to the lung. (A) Expression of ADAM17 (red lines) in the metastatic microenvironment of WT and hypomorphic ADAM17 ex/ex mice in the experimental model used in this study. Note that ADAM17 expression is not altered on injected TCs. (B) Experimental outline for experiments in C-F. Syngeneic TCs are injected i.v. into the tail vein of the indicated mouse lines. TCs expressing LacZ are used in C and D, and mice were sacrificed $6 \mathrm{~h}$ after TC injection, while parental TCs are used in E and F, and mice were sacrificed 3 wk after TC injection. (C and D) Extravasated TCs were quantified by $\beta$-Gal staining $6 \mathrm{~h}$ after TC injection. Representative microscopic images are shown. Scale bars represent $50 \mu \mathrm{m} . n=3-4$ mice/group. ${ }^{*}, \mathrm{P}<0.05$ $(C) ; P=0.12$ (D) by two-sided Wilcoxon rank sum test with continuity correction. (E and F) $21 \mathrm{~d}$ after TC injection, lung metastases were counted. Representative lung images $21 \mathrm{~d}$ after TC injection are shown. Scale bar indicates $5 \mathrm{~mm} . n=8-9$ mice/group $(\mathrm{E})$ and 6 mice/group $(\mathrm{F}) .{ }^{*}, \mathrm{P}<0.05 ;{ }^{* *}, \mathrm{P}<0.01$ by unpaired two-tailed bootstrap $t$ test based on 5,000 Monte Carlo simulations. (G) Kaplan-Meier survival curves for WT and ADAM17ex/ex mice demonstrate that ADAM17 is essential for metastasis-induced death. $n=15$ mice/group. ${ }^{* * *}, \mathrm{P}<0.0001$. Data represent mean \pm SEM. p.i., postinjection. 
A

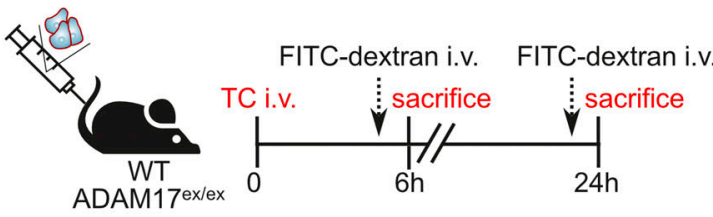

B

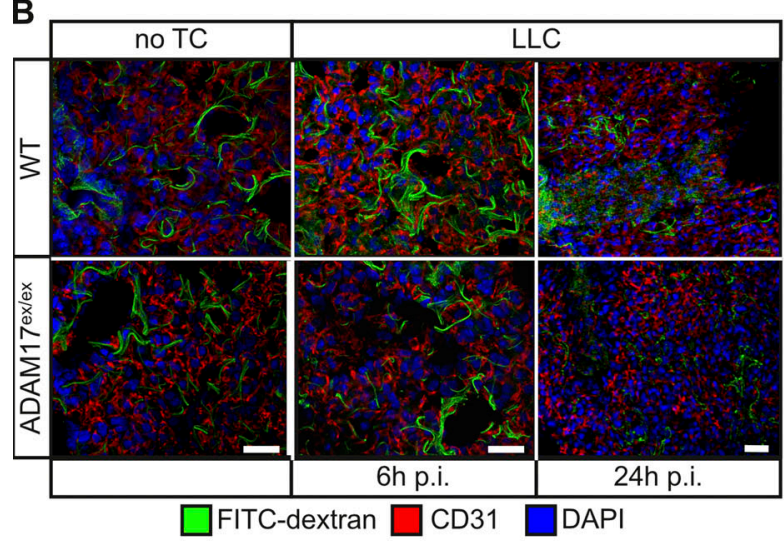

D
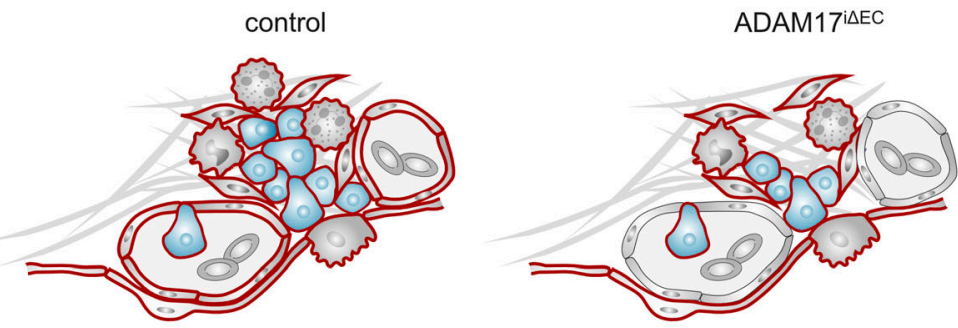

C

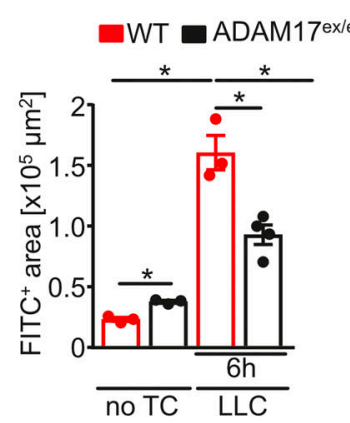

MDA-MB231

(CFSE')
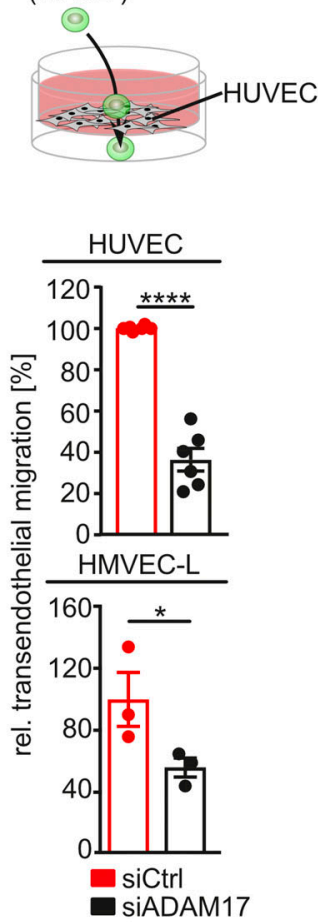

E

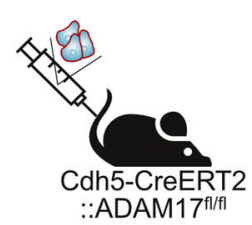

TAM/EtOH

i.p.

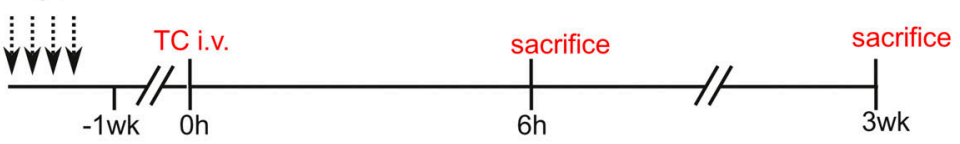

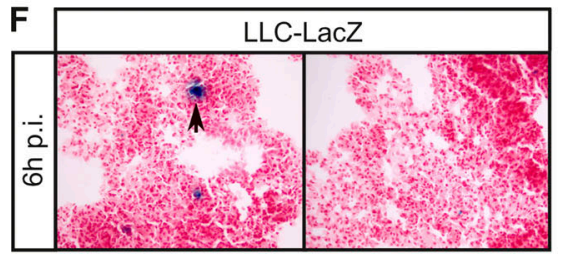

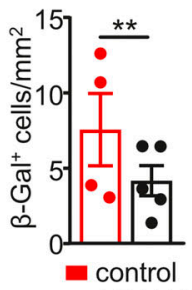

- ADAM17i $1 \triangle \mathrm{EC}$
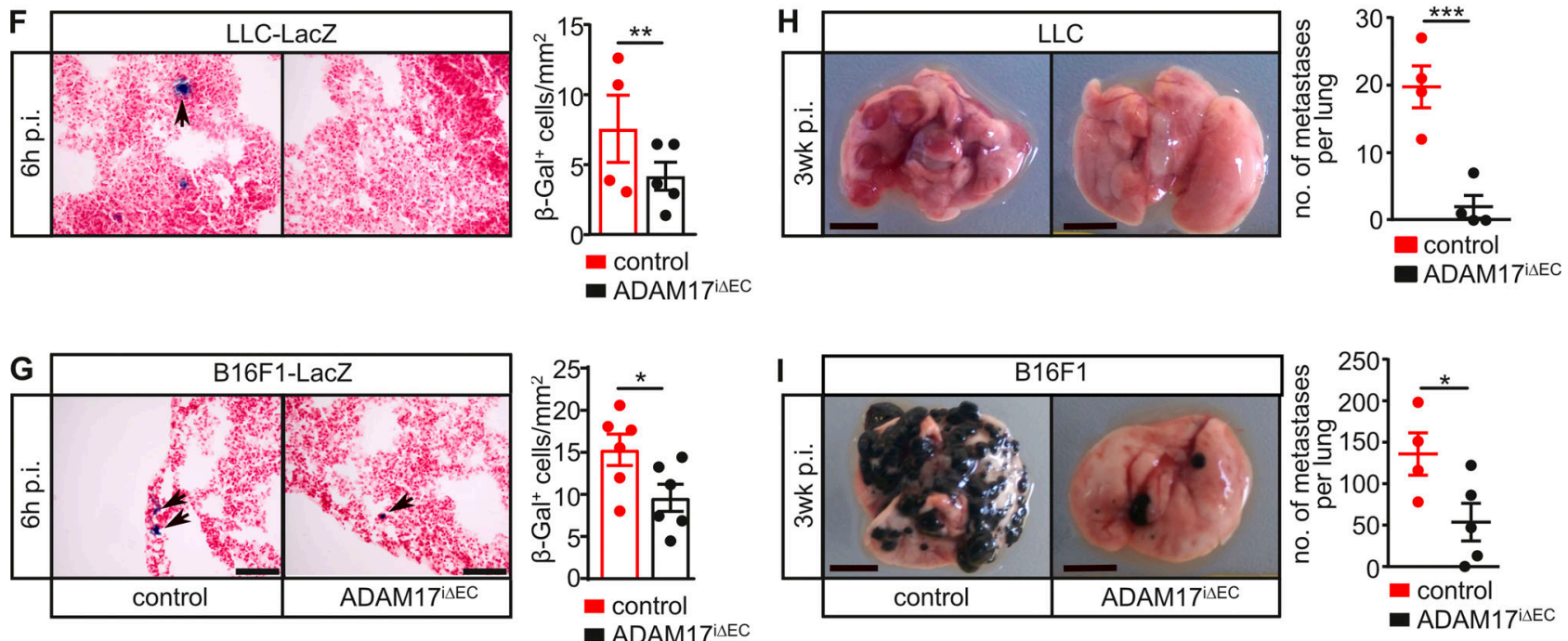

Figure 2. TC-induced endothelial permeability is promoted by ADAM17. (A) Experimental outline as performed in B. Parental LLC or B16F1 TCs were i.v. injected into the indicated mouse strains. 6 or $24 \mathrm{~h}$ later, FITC-labeled dextran was i.v. injected 10 min before sacrificing. (B) Confocal images of lung sections stained for the indicated markers. FITC ${ }^{+}$area was quantified as a measure of vascular permeability. Scale bar indicates $25 \mu \mathrm{m} . n=3 \mathrm{mice} / \mathrm{group}$ (top), $n=4$ mice/group (bottom), with six images per section quantified. *, $\mathrm{P}<0.05$ by one-way ANOVA on ranks with Dunn's post hoc test. (C) Transendothelial migration of CFSE-labeled MDA-MB231 TCs through monolayers of HUVEC or HMVEC-L with siRNA-mediated knockdown of ADAM17. Shown is the quantification of six 
(HUVEC) or three (HMVEC-L) independent experiments. ${ }^{*}, \mathrm{P}<0.05{ }^{* * * *}, \mathrm{P}<0.0001$ by unpaired two-tailed $t$ test with Welch's correction. (D) Tamoxifen (TAM) injection into Cdh5-CreERT2::ADAM17 flox/flox mice results in ADAM17 ${ }^{\mathrm{AEC}}$. Note that all other cells in the metastatic microenvironment express ADAM17. (E) Experimental outline as performed in F-I. To induce ADAM17 ${ }^{\mathrm{i} E \mathrm{EC}}$, mice received four consecutive tamoxifen injections. Control animals were injected with vehicle (EtOH/oil). $7 \mathrm{~d}$ later, TCs were injected i.v. into the tail vein of the indicated mouse lines. TCs expressing LacZ were used in F and G, and mice were sacrificed $6 \mathrm{~h}$ after TC injection, while parental TCs were used in $\mathrm{H}$ and I and mice were sacrificed 3 wk after TC injection. (F and G) Extravasated TCs were quantified by $\beta$-Gal staining. Representative microscopic images are shown. Scale bar indicates $50 \mu \mathrm{m} . n=4-6$ mice/group. ${ }^{*}, \mathrm{P}<0.05 ;{ }^{*}$, $\mathrm{P}<0.01$ by twofactorial ANOVA with group as fixed factor (F) or signed rank test based on 5,000 Monte Carlo simulations (G). (H and I) 3 wk after TC injection, lung metastases were counted. Representative lung images $21 \mathrm{~d}$ after TC injection are shown. Scale bar indicates 5 mm. $n=4-5$ mice/group. ${ }^{*}, \mathrm{P}<0.05 ;{ }^{* * *}, \mathrm{P}<$ 0.001 by unpaired two-tailed Student's $t$ test with Welch's correction. Data represent mean \pm SEM. Ctrl, control; p.i., postinjection; rel. relative.

significantly reduced upon siRNA-mediated ADAM17 suppression in ECs (Fig. 2 C and Fig. S2 A). To test the hypothesis that EC-derived ADAM17 controls TC extravasation in vivo, we generated mice with an EC-specific ADAM17 deficiency (ADAM17 ${ }^{\mathrm{IEC}}$; Fig. 2 D; and Fig. S2, C-E) using tamoxifen-inducible Cdh5-CreERT2 mice (Sörensen et al., 2009). Indeed, TC extravasation was significantly lowered in ADAM17i $\triangle \mathrm{EC}$ mice (Fig. 2, E-G), and tumor burden was reduced to a similar extent as in ADAM17 ex/ex mice 3 wk after TC inoculation (Fig. 2, $\mathrm{H}$ and I). We detected ADAM17 expression in ECs of human lung metastases irrespective of the primary tumor entity (Fig. S1 C), which is compatible with a critical role of endothelial ADAM17 in human metastasis. Taken together, while previous reports have observed a role of TC-derived ADAM17 for primary tumor growth, we demonstrate here that EC-derived ADAM17 in the metastatic microenvironment is essential for $\mathrm{TC}$ extravasation and the establishment of metastatic colonies.

\section{ADAM17 confers TC-induced EC death}

TC-induced EC death is one mechanism that is discussed to mediate vascular permeability preceding TC extravasation (Hänggi et al., 2017; Hou et al., 2019; Yang et al., 2019; Patel et al., 2020). We therefore assessed whether TC-dependent EC death induction depends on ADAM17 on the basis of ethidium homodimer III (EthDIII) uptake into cells with impaired membrane integrity, as previously described (Strilic et al., 2016). Cocultivation of HUVECs with fluorescently labeled MDA-MB231 breast cancer cells (Fig. $3 \mathrm{~A}$ ) resulted in a significantly lower level of EthDIII incorporation into HUVECs with siRNA-mediated suppression of ADAM17 compared with ADAM17-competent control cells (Fig. 3 B). Similar results were obtained when LacZexpressing B16F1 or LLC murine TCs were cultivated on murine microvascular lung ECs (MLECs; Fig. $3 \mathrm{C}$ and Fig. S2 B). Accordingly, EthDIII incorporation into CD31+ lung ECs but not into $\mathrm{TTF}^{+}$pneumocytes $6 \mathrm{~h}$ after TC injection was significantly reduced in ADAM17ex/ex mice, almost to the same level as in necroptosis-deficient RIPK3 ${ }^{-/-}$mice (Fig. 3, D-F). Consistent with the assumption of a cell-autonomous effect of ADAM17, ECspecific ADAM17 deficiency in ADAM17 ${ }^{\mathrm{B} E \mathrm{EC}}$ mice was sufficient to suppress TC-induced EC death during TC extravasation (Fig. 3, G-I).

\section{Both EC- and TC-derived TNF promote TC extravasation and metastasis}

TNF secreted from myeloid cells was previously demonstrated to promote lung metastasis (Kim et al., 2009). We therefore hypothesized that ADAM17-mediated TNF release from myeloid cells regulates metastasis. However, while we detected a significant reduction of TNF release from ADAM17-deficient bone marrow-derived macrophages and neutrophils (Fig. S1, D-F), metastases burden was not reduced in mice exhibiting a myeloidspecific ADAM17 deficiency (Fig. S1, G-I). We therefore concluded that myeloid-derived TNF is dispensable for metastasis.

In contrast, siRNA-mediated suppression of TNF in both human (Fig. 4 A) and murine ECs (Fig. 4 B) reduced TC-induced cell death in vitro, indicating that EC-derived TNF promotes TCinduced EC death (Fig. 4 C). In line with the assumption that TNFR1 mediates TNF-induced cell death signaling, we observed significantly reduced TC-induced EC death in vitro in HUVECs with siRNA-mediated suppression of TNFR1 (Fig. 4 D). Consequently, the number of extravasated TCs in vivo was significantly lower in TNFR1 $^{-/-}$mice compared with WT animals (Fig. 4, E and F).

We furthermore assessed whether TC-derived TNF contributes to metastasis in our model (Fig. $5 \mathrm{~A}$ ). We detected low-level TNF on the surface (Fig. 5 B) and in the supernatant (Fig. S4, A and B) of all three TC lines used in this study. We therefore generated LacZ-expressing LLC and B16F1 TCs with a genetic deficiency in TNF using CRISPR/Cas9. We targeted Tnf exon 1 with a multiguide approach (Fig. S3 A), which resulted in a 110bp deletion (Fig. S3, B-D), leading to a premature stop codon (Fig. S3 D). TC-specific TNF deficiency did not alter TC-induced MLEC death in an in vitro coculture assay (Fig. S3 E). Similarly, TC-induced EC death in vivo was not altered in the absence of TC-derived TNF (Fig. 5, C and D). In contrast, TC extravasation was significantly reduced in the absence of TC-derived TNF (Fig. 5, C and E). Consequently, metastasis formation was largely reduced in the absence of TC-derived TNF $3 \mathrm{wk}$ after injection (Fig. 5 F), suggesting that TC survival in vivo depends on a lowlevel TNF autocrine loop. We indeed observed a slightly increased susceptibility toward TNF-induced cell death in the absence of TC-derived TNF for LLC-LacZ cells (Fig. $5 \mathrm{G}$ ).

We next assessed whether pharmacological blockade of TNF signaling prevents TC extravasation. TC-induced EC death in vitro in the HUVEC/MDA-MB231 coculture model was significantly reduced when TNF was neutralized by binding to etanercept, a recombinant form of the soluble human TNFR2 ectodomain fused to a human Fc-tag (Fig. 6, A and B; Moreland et al., 1997). TC-induced EC death in vivo was significantly lowered when etanercept was administered to mice 5 min before TC injection (Fig. 6, C and D). Consequently, TC extravasation was significantly reduced but not completely absent when TNF was neutralized by etanercept (Fig. 6 E).

Taken together, while TC-derived TNF seems to be essential for CTC survival, EC-derived TNF is crucial for TC-induced EC 


\section{מ JEM}

A MDA-MB231

LLC-LacZ, B16F1-LacZ
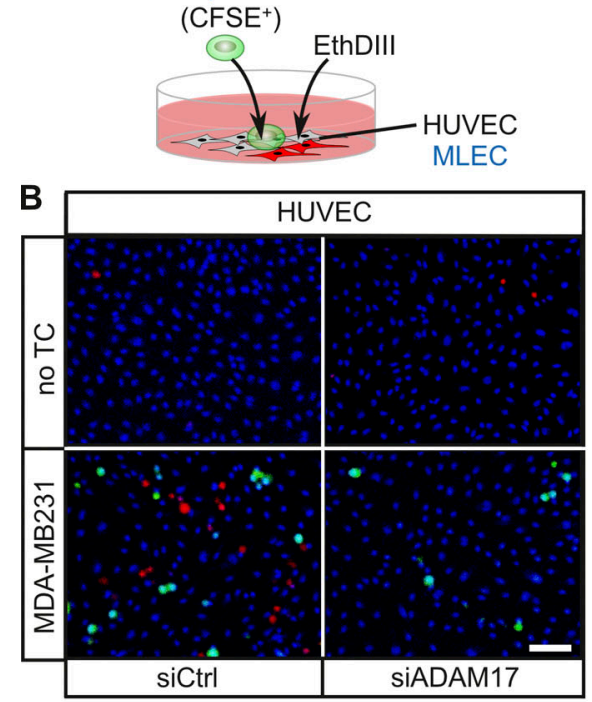

口EthDIII DH33342 口MDA-MB231

D

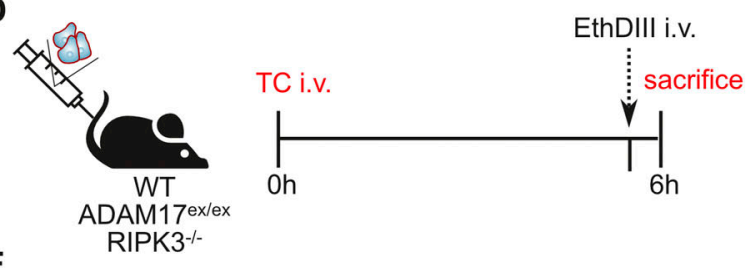

E

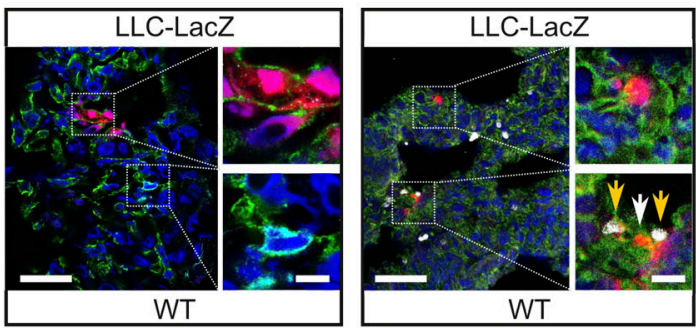

口EthDIII QDAPI QCD31 पTTF1 $\square \beta$-Gal
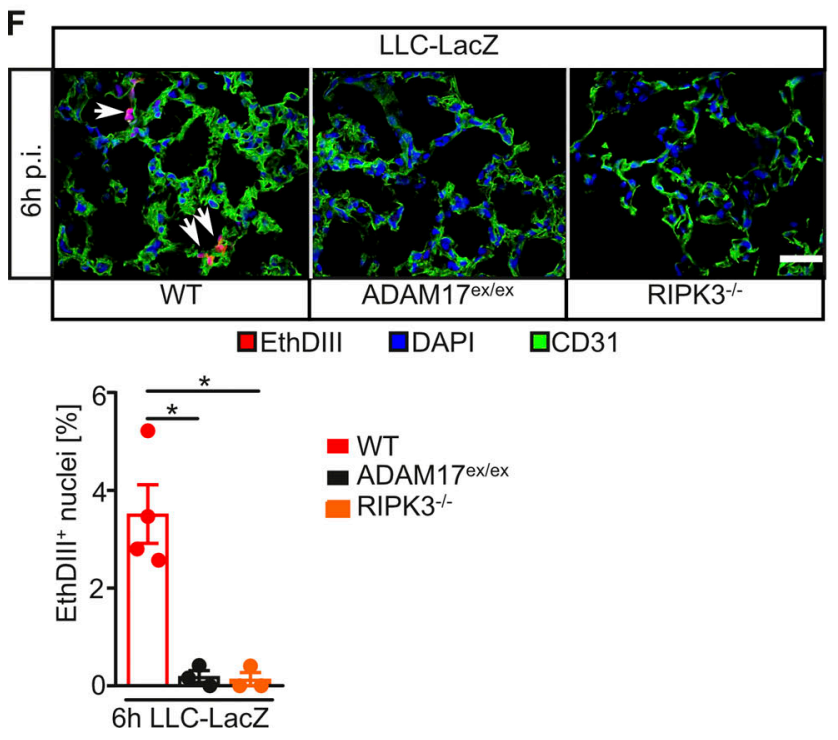

C
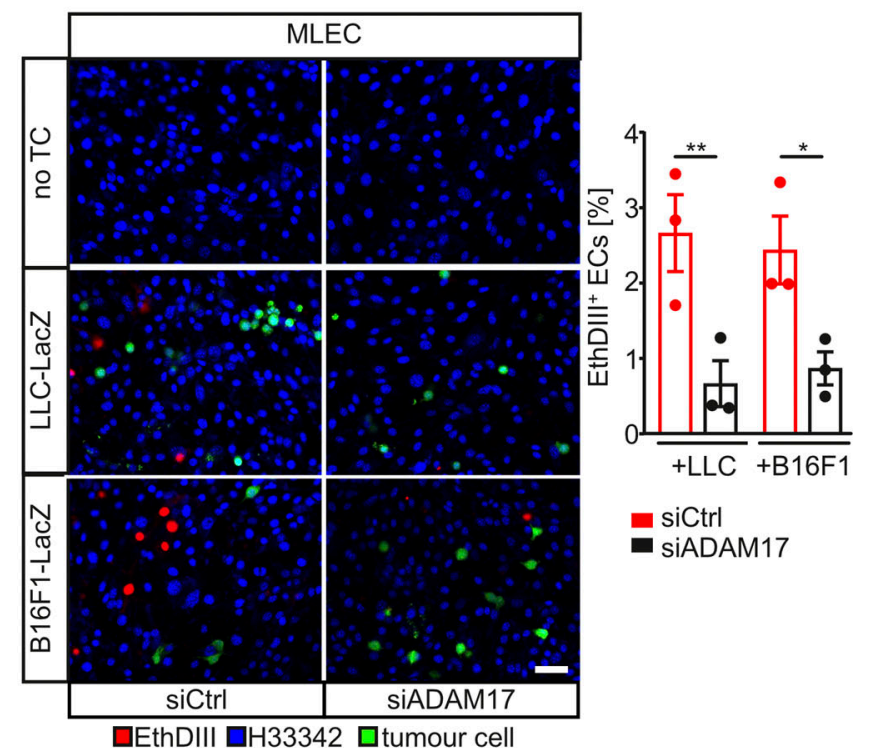

- siCtrl

- siADAM17

\section{G}
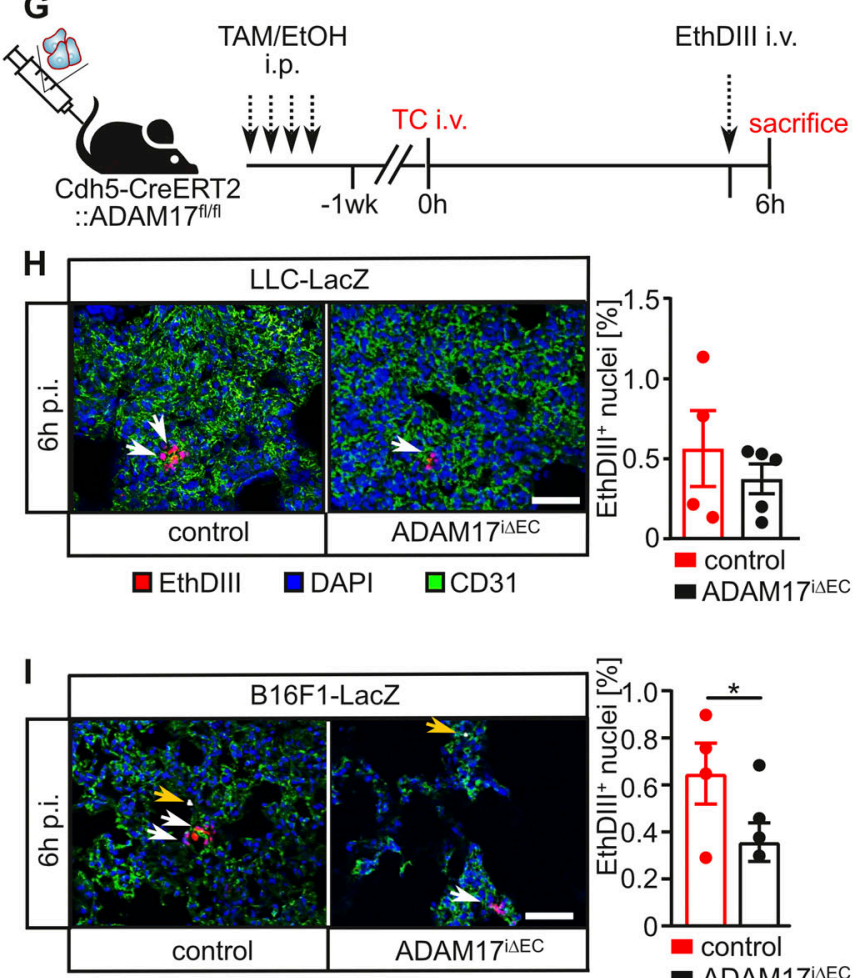

口EthDIII

DDAPI

- ADAM17LEEC

Figure 3. ADAM17 is essential for TC-induced EC death. (A) HUVECs (human) or MLECs (murine) with indicated siRNA-mediated knockdown were cocultured with CFSE-labeled MDA-MB231 (human) or B16F1-LacZ or LLC-LacZ (murine) TCs, respectively, and cells with impaired membrane integrity were determined after $6 \mathrm{~h}$ by EthDIII uptake. (B) Shown are representative confocal images of cocultures of MDA-MB231 on HUVECs with the indicated genetic 
deficiency and quantification of four independent experiments with three technical replicates and three images per replicate analyzed. Scale bar indicates 100 $\mu \mathrm{m} .{ }^{* * *}, \mathrm{P}<0.001$ by unpaired two-tailed Mann-Whitney $U$ test. (C) Shown are representative confocal images of LLC-LacZ or B16F1-LacZ cocultured on MLECs with the indicated genetic deficiency and the quantification of three independent experiments with three technical replicates and three images per replicate analyzed. Scale bar indicates $100 \mu \mathrm{m} .{ }^{*}, \mathrm{P}<0.05 ;{ }^{* *}, \mathrm{P}<0.01$ by one-way ANOVA with Tukey's post hoc test. (D) Experimental outline as performed in E and F. LacZ-expressing LLC TCs were i.v. injected into the indicated mouse strains. 6 h later, EthDIII was i.v. injected 5 min before sacrificing. (E) Representative confocal image of lung sections for the indicated markers indicates cell death in CD31+ ECs but not in TTF1 type II pneumocytes. Scale bar indicates $25 \mu \mathrm{m}$ in the overview and $5 \mu \mathrm{m}$ in the enlarged view. White arrows indicate EthDIII+ CD31+ cells, and yellow arrows indicate $\beta$-Gal ${ }^{+} \mathrm{TCs}$. (F) Pulmonary EthDIII+ ECs were quantified from confocal images of lung sections stained for the indicated markers. Scale bar indicates $50 \mu \mathrm{m}$. White arrows indicate EthDIII+CD31+ cells. $n=3$ mice/group, with three to six sections per mouse and at least three images per section analyzed. ${ }^{*}, P<0.05$ by one-way ANOVA on ranks with Dunn's post hoc test. (G) Experimental outline as performed in $\mathrm{H}$ and I. To induce EC-specific ADAM17 deficiency, mice received four consecutive tamoxifen (TAM) injections. Control animals were injected with vehicle (EtOH/oil). $7 \mathrm{~d}$ later, LacZ-expressing LLC TCs were i.v. injected into the indicated mouse strains. $6 \mathrm{~h}$ after TC injection, EthDIII was i.v. injected $5 \mathrm{~min}$ before sacrificing. ( $\mathrm{H}$ and $\mathrm{I})$ Pulmonary EthDIII+ ECs were quantified from confocal images of lung sections stained for the indicated markers. Scale bar indicates $50 \mu \mathrm{m}$. White arrows indicate EthDIII+CD31 ${ }^{+}$cells, and yellow arrows indicate $\beta-\mathrm{Gal}{ }^{+} \mathrm{TCs}$. $n=3-5$ mice/ group with three to six sections per mouse and at least three images per section analyzed. ${ }^{*}, \mathrm{P}<0.05$, unpaired two-tailed bootstrap $t$ test based on 5,000 Monte Carlo simulations (H) or generalized linear model based on log-normal distributions (I). Data represent mean \pm SEM. Ctrl, control; p.i., postinjection.

death. Therefore, TNF is a druggable target for the prevention of tumor metastasis.

\section{ADAM17 is essential for TNFR1-mediated necroptosis}

On the basis of the cell-autonomous effect of ADAM17 in ECs for TC-induced cell death, we next hypothesized that ADAM17 activity is a general prerequisite for TNF-induced cell death. We therefore induced necroptosis in WT or ADAM17 ${ }^{\text {ex/ex }}$ murine embryonic fibroblasts ( $\mathrm{mEFs}$ ) by administration of TNF and the pancaspase inhibitor carbobenzoxy-valyl-alanyl-aspartyl[O-methyl]-fluoromethylketone (zVAD), as previously described (Lafont et al., 2018). TNF/zVAD-induced cell death was drastically impaired in ADAM17ex/ex mEFs (Fig. $7 \mathrm{~A}$ ), indicating that ADAM17 is required for TNFR1-induced necroptosis. Also in HUVECs, TNF/zVAD-induced cell death was significantly reduced when ADAM17 expression was suppressed (Fig. 7 B). This led to the hypothesis that canonical NF- $\kappa \mathrm{B}$ signaling might prevent cell death induction in the absence of ADAM17. Phosphorylation of I $\mathrm{k}$ by I $\mathrm{k} B$ kinase induces ubiquitin-dependent proteasomal degradation of I $\mathrm{I} B$ and subsequent translocation of a NF- $\kappa B$ heterodimer, such as $\mathrm{p} 50 / \mathrm{p} 65$, to the nucleus to enable transcription of NF- $\kappa B$ target genes (Napetschnig and Wu, 2013). In line with a protective role of NF- $\kappa B$ signaling in ADAM17deficient cells, we observed comparable levels of cell death induction in control cells and HUVECs with siRNA-mediated suppression of ADAM17 upon inhibition of IkB kinase with the small molecule TPCA-1 (Fig. 7 B). This correlated with ligandindependent p65 phosphorylation in ADAM17ex/ex $\mathrm{mEFs}$, while in WT MEFs, p65 phosphorylation was only detectable upon TNF stimulation (Fig. 7 C). Interestingly, ligand-dependent IkB phosphorylation and concomitant I $\mathrm{B}$ degradation were only observed in WT $\mathrm{mEFs}$, while I $k B$ levels remained unchanged in ADAM17 ${ }^{\text {ex/ex }} \mathrm{mEFs}$ (Fig. 7 C). Nuclear localization of the NF- $\kappa$ B subunit p65 and activation of an NF- $\kappa B$ reporter construct was significantly elevated in ADAM17 ${ }^{\text {ex/ex }} \mathrm{mEFs}$ compared with WT mEFs (Fig. $7 \mathrm{D}$ and Fig. S4 C). In the same line, NF- $\kappa$ B target genes, such as Tnf, Cflar, and Birc3, were constitutively elevated in ADAM17ex/ex mEFs compared with WT mEFs, which showed increased NF- $\kappa$ B target gene levels only after TNF stimulation (Fig. 7 E). Taken together, our data suggest a constitutive noncanonical NF- $\kappa$ B activation in the absence of ADAM17.

\section{Proteolytic processing of TNFR1 is essential for cell death induction}

We next tested whether TNFR2 mediates protective effects in the absence of ADAM17. We therefore suppressed TNFR2 expression in HUVECs by siRNA and simultaneously inhibited ADAM17 activity using the hydroxamate-type metalloproteinase inhibitor TAPI-1. TC-induced EC death was only slightly increased when TNFR2 expression was downregulated by siRNA (Fig. S4 D). In contrast, inhibition of ADAM17 activity by TAPI1 resulted in impaired TC-induced EC death to the same extent as siRNA-mediated suppression of ADAM17 in both TNFR2proficient HUVECs and those with siRNA-mediated suppression of TNFR2 (Fig. S4 D). We therefore hypothesized that instead, proteolytic processing of TNFR1 by ADAM17 might be essential for TC-induced EC death. Accordingly, levels of soluble TNFR1 (sTNFR1) in the supernatant of HUVECs with ADAM17 suppression (Fig. S4 E), cocultivated with TCs, as well as in the supernatant of TNF-stimulated mEFs (Fig. S4 F), were significantly reduced. Furthermore, sTNFR1 plasma levels $6 \mathrm{~h}$ after TC injection were reduced in ADAM17 ${ }^{\text {ex/ex }}$ mice (Fig. S4 G). In line with these data, appearance of a TNFR1 C-terminal fragment was reduced in ADAM17ex/ex mEFs (Fig. S4 H), as well as in ADAM17deficient HEK293 cells (Fig. S4 I). To test our hypothesis, we generated ADAM17 cleavage-resistant TNFR1 mutants (Fig. $8 \mathrm{~A}$ ) by substituting the $\mathrm{P1}^{\prime}$ valine at the ADAM17 cleavage site by proline, as previously described (Brakebusch et al., 1994). When transfected into HEK293 cells, proteolytic processing of TNFR1 V202P was almost completely impaired and to the same extent as processing of TNFR1 WT in ADAM17-deficient HEK293 cells (Fig. S4 K). While expression of both TNFR1 variants was comparable in reconstituted TNFR1 ${ }^{-1-} \mathrm{mEFs}$ (Fig. 8 B), cell surface levels of TNFR1 V202P were slightly elevated compared with TNFR1 WT (Fig. 8 C). In line with our hypothesis, TNF/ zVAD-induced necroptosis was significantly reduced in TNFR1 V202P-reconstituted mEFs and lowered to a similar extent as in ADAM17ex/ex mEFs (Fig. 8 D). Accordingly, ligand-induced RIPK3 phosphorylation was impaired in TNFR1 V202Preconstituted mEFs (Fig. 8 E). These data indicate that ADAM17-mediated ectodomain shedding of TNFR1 is important for TNF-induced cell death. In support of this notion, we observed a strongly reduced association of RIPK1 and cleaved 


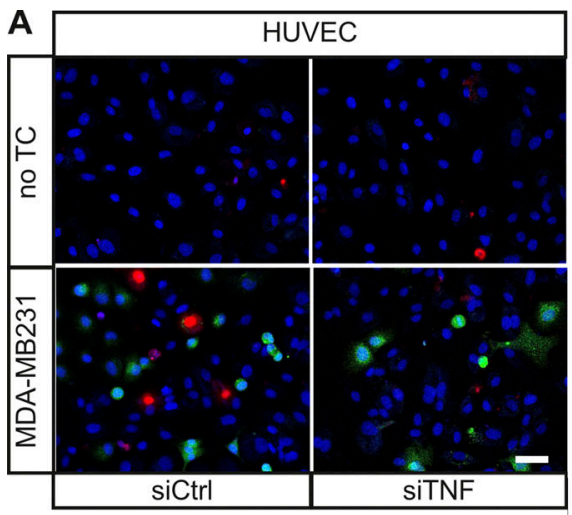

口EthDIII घH33342 口MDA-MB231

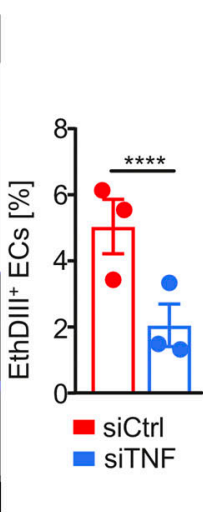

c

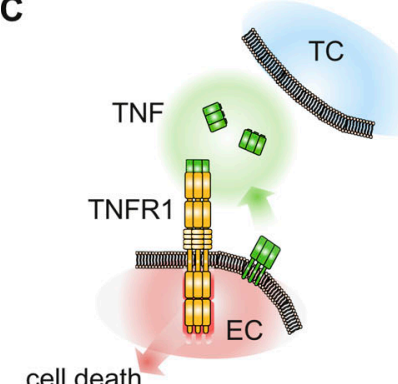

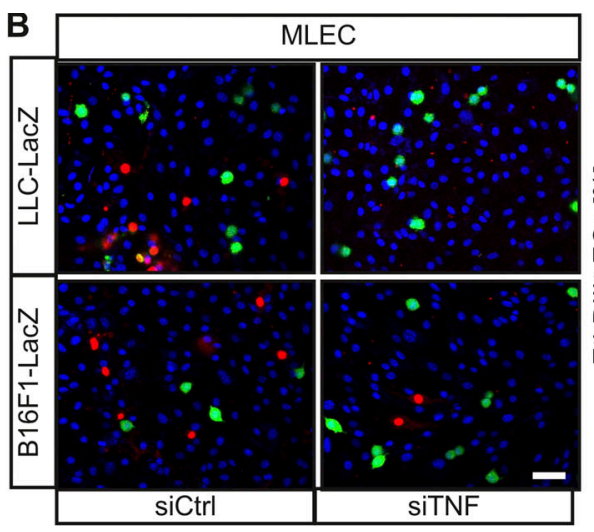

口EthDIII $\square \mathrm{H} 33342$ 口tumor cell
D

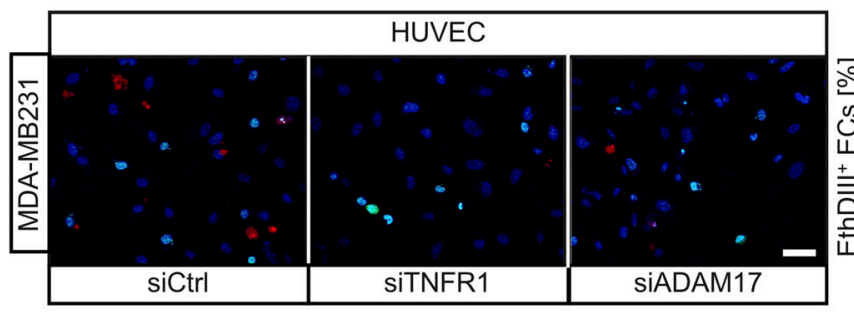

口EthDIII $\square \mathrm{H} 33342$ MMDA-MB231

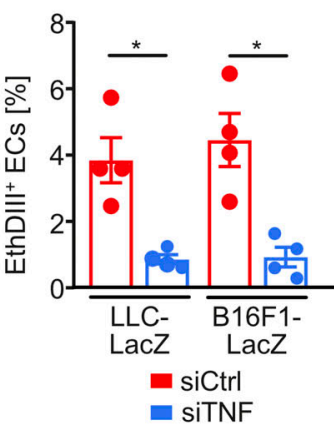

a siTNF

Figure 4. EC-derived TNF is necessary for TC-induced EC death. (A) HUVECs with siRNA-mediated TNF knockdown were cocultured with CFSE-labeled MDA-MB231 TCs, and cells with impaired membrane integrity were determined after $6 \mathrm{~h}$ by EthDIII uptake. Shown are representative images and the quantification of three independent experiments. Three technical replicates per experiment with three to four images per replicate were analyzed. Scale bar indicates $50 \mu \mathrm{m} .{ }^{* * * *}, \mathrm{P}<0.0001$ by semiparametric generalized linear model based on log-normal distributions. (B) Murine MLECs with siRNA-mediated TNF knockdown were cocultured with the indicated CFSE-labeled murine TCs. Cells with impaired membrane integrity were determined after $6 \mathrm{~h}$ by EthDIII uptake. Shown are representative images and the quantification of four independent experiments. Three technical replicates per experiment with three to four images per replicate were analyzed. Scale bar indicates $50 \mu \mathrm{m}$. ${ }^{*}, \mathrm{P}<0.05$ by unpaired two-tailed Mann-Whitney $U$ test. (C) Contact with TCs might induce an autocrine soluble TNF loop in ECs, leading to EC death. (D) HUVECs with indicated siRNA-mediated knockdown were cocultured with CFSE-labeled MDA-MB231 TCs, and cells with impaired membrane integrity were determined after $6 \mathrm{~h}$ by EthDIII uptake. Shown are representative images of three independent experiments. Three technical replicates per experiment with three to four images per replicate were analyzed. Scale bar indicates $50 \mu \mathrm{m}$. ${ }^{* * *}, \mathrm{P}<0.001$ by one-way ANOVA on ranks with Dunn's post hoc test. (E) Experimental outline as performed in F. LacZ-expressing LLC TCs were i.v. injected into the indicated mouse strains, and TC extravasation was assessed after 6 h. (F) Extravasated TCs 6 h after TC injection were quantified by $\beta$-Gal staining. Representative microscopic images are shown. Scale bar indicates $50 \mu \mathrm{m} . n=3$ mice/group. ${ }^{* * *}, \mathrm{P}<0.001$ by unpaired Student's $t$ test. Data represent mean \pm SEM. Ctrl, control; $p . i$, postinjection.

caspase 8 to the adaptor protein FADD (Fig. $8 \mathrm{~F}$ ), indicating impaired TNFR1 complex II and necrosome formation.

Ectodomain shedding of transmembrane proteins is often followed by regulated intramembrane proteolysis (RIP). The $\gamma$-secretase complex with its catalytic subunits presenilin (PSEN) 1 and 2 is a major mediator of RIP (Oikawa and Walter, 2019) and is involved in TNFR1 processing (Fig. 8 G; Chhibber-Goel et al., 2016). In support of this notion, we observed that TNF/zVAD-induced necroptosis was significantly reduced in $\mathrm{PSEN1}^{+/-} 2^{-/-} \mathrm{mEFs}$
(Fig. $8 \mathrm{H}$ ). Taken together, our data suggest that ADAM17mediated ectodomain shedding and subsequent $\gamma$-secretase-mediated RIP of TNFR1 is a prerequisite for TNF-induced cell death.

\section{Pharmacological inhibition of ADAM17 is sufficient to block metastasis}

We further sought to explore whether pharmacological inhibition of ADAM17 is sufficient to block TC-induced EC death in vivo and, in consequence, CTC extravasation and metastasis. 
A

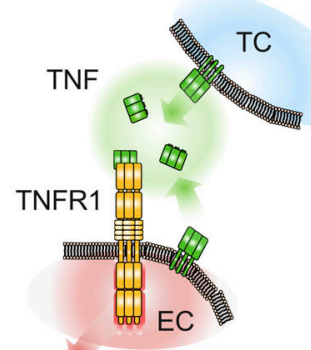

B

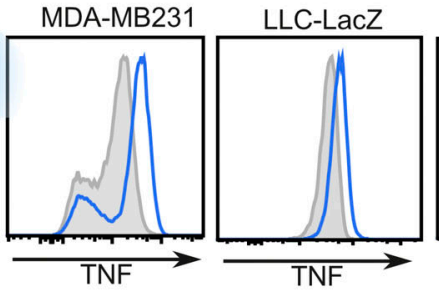

C

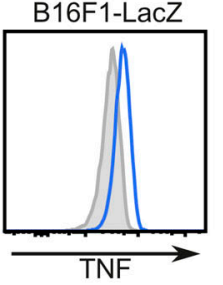

B16F1-LacZ, B16F1-LacZ TNFko LLC-LacZ, LLC-LacZ TNFko

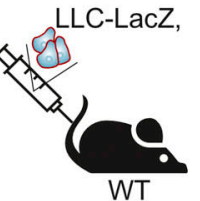

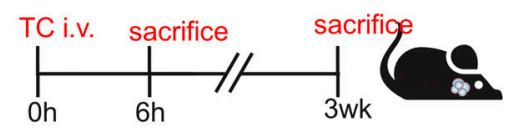

cell death
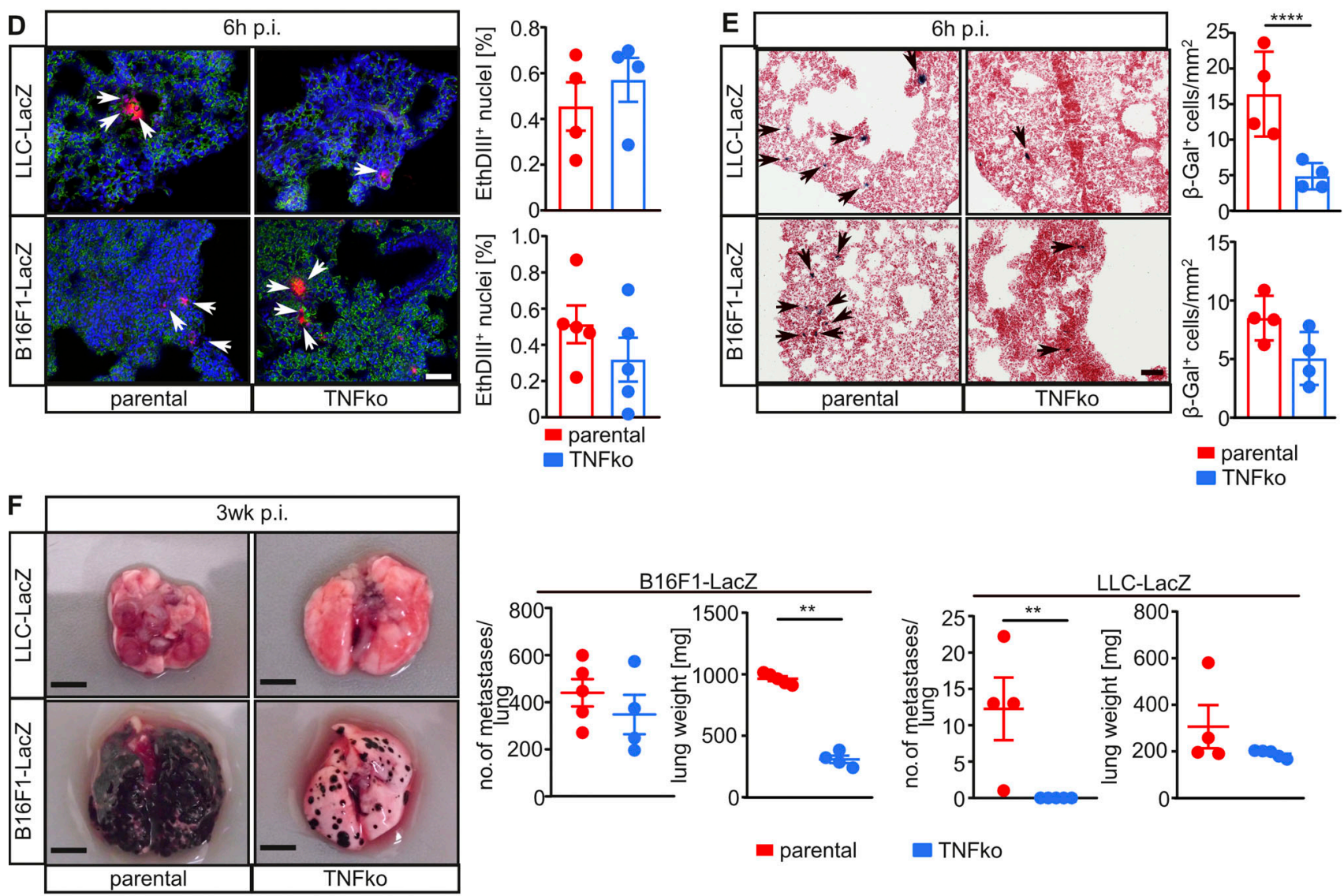

a parental TNFko
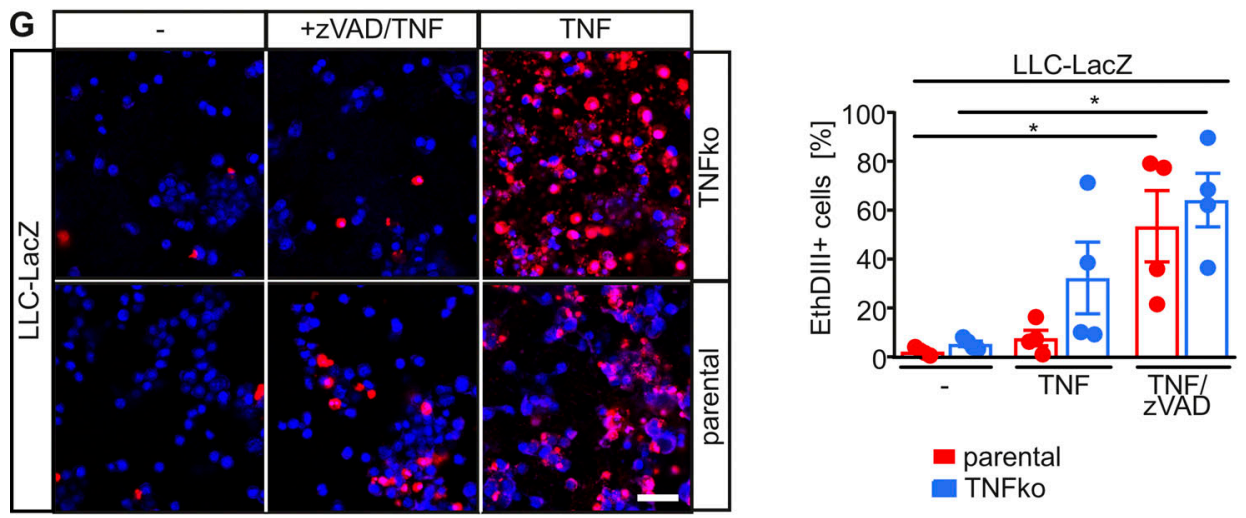

口EthDIII $\mathrm{H} 33342$

Figure 5. TC-derived TNF is dispensable for TC-induced EC death but required for metastasis. (A) TCs can produce membrane-bound or soluble TNF-a that can directly bind to TNFR1 on ECs to induce EC death and promote endothelial permeability. (B) TCs used in this study express very-low-level TNF as assessed by flow cytometry using anti-TNF antibodies. (C) Experimental outline as performed in D-G. TNF-deficient (TNFko) LacZ-expressing LLC or B16F1 TCs were generated by CRISPR/Cas9 (Fig. S3). Parental or TNF-deficient (TNFko) LacZ-expressing LLC or B16F1 TCs were i.v. injected into the indicated mouse 
strains. $6 \mathrm{~h}$ later, EthDIII was i.v. injected 5 min before sacrificing, where indicated ( $\mathrm{E}$ and $\mathrm{F}$ ). $21 \mathrm{~d}$ after injection, lung metastases were determined ( $\mathrm{G}$ ). (D) Pulmonary EthDIII+ ECs were quantified from confocal images of lung sections stained for the indicated markers. Scale bar indicates 50 mm. White arrows indicate EthDIII+ ECs. $n=4-5$ mice/group; unpaired two-tailed Mann-Whitney $U$ test. (E) Extravasated TCs 6 h after TC injection were quantified by $\beta$-Gal staining. Representative microscopic images are shown. Scale bar indicates $100 \mu \mathrm{m}$. Black arrows indicate extravasated TCs. $n=4-5$ mice/group. ${ }^{* * *}, \mathrm{P}<$ 0.0001 by unpaired two-tailed generalized linear model based on $\mathrm{y}$-distributions. (F) 3 wk after TC injection, lung metastases were counted. Representative lung images $21 \mathrm{~d}$ after TC injection are shown. $n=4-5$ mice/group. ${ }^{* *}, \mathrm{P}<0.01$ by two-tailed Mann-Whitney $U$ test. (G) LLC-LacZ TCs with the indicated genotype were incubated where indicated with $100 \mu \mathrm{M}$ zVAD 15 min before stimulation with $50 \mathrm{ng} / \mathrm{ml}$ TNF. Cells with impaired membrane integrity were determined after $6 \mathrm{~h}$ by EthDIII uptake. Shown are representative images and the quantification of four independent experiments with three technical replicates and three to four images per replicate analyzed. Scale bar indicates $50 \mu \mathrm{m} .{ }^{*}, \mathrm{P}<0.05$ by Welch's ANOVA with Tukey's post hoc test. Data represent mean \pm SEM. p.i., postinjection.

To this end, we used the ADAM17 inhibitor TAPI-1 and the recently developed, highly specific inhibitory recombinant ADAM17 PD (Fig. 9 A; Wong et al., 2016). Proteolytic removal of the inhibitory PD from the ADAM17 proenzyme in the Golgi during maturation renders ADAM17 catalytically competent (Scheller et al., 2011; Wong et al., 2015). ADAM17 PD shares almost no homology with other PDs of the ADAM or matrix metalloproteinase family, making recombinant ADAM17 PD a suitable candidate for highly specific ADAM17 inhibition (Wong et al., 2016). TAPI-1 or ADAM17 PD impaired ADAM17 activity in vitro at an half maximal inhibitory concentration $\left(\mathrm{IC}_{50}\right)$ of $128.0 \pm 0.9 \mathrm{nM}$ and $110.8 \pm 1.6 \mathrm{nM}$, respectively (Fig. S5, A-D). We administered a single dose of TAPI-1 or ADAM17 PD i.v. 5 min before TC injection (Fig. 8 B) and observed significantly reduced lung EC necroptosis $6 \mathrm{~h}$ after TC injection (Fig. $9 \mathrm{C}$ ). Accordingly, TC extravasation was significantly reduced in inhibitor-treated animals (Fig. 9 D). Consequently, injection of a single dose of ADAM17 PD before TC injection had long-term effects in mice. Mice with ADAM17 PD injection showed a markedly reduced tumor burden in the lung, and partially in liver and kidney (Fig. S5 E), 3 wk after TC injection (Fig. 9 E). Taken together, shortterm pharmacological inhibition of ADAM17 activity is sufficient to prevent long-term metastatic seeding to the lung.

\section{Discussion}

Here, we describe a previously unknown essential role of ADAM17 in the metastatic microenvironment, leading to a novel concept of antimetastatic therapy. We demonstrate that efficient formation of metastases depends on extravasation of TCs, which requires ADAM17 activity in ECs. Mechanistically, TC- and TNFinduced cellular necroptosis largely depend on ADAM17-mediated proteolytic processing of death receptor TNFR1. Genetic loss of ADAM17 in ECs or inhibition of ADAM17 catalytic activity is therefore sufficient to (i) prevent TC-induced EC necroptosis, (ii) lower TC extravasation, and (iii) protect from metastases formation in two syngeneic hematogenic metastasis models.

Albeit tumor metastasis is the major cause of death in cancer patients, there are currently no clinically approved drugs available that specifically target steps of the metastatic cascade (Strilic and Offermanns, 2017). This is also due to the fact that beneficial effects of therapeutic inhibition of a particular pathway during metastasis are difficult to predict. For example, antiCCL2 monotherapy reduces metastasis of mammary carcinoma but promotes tumor progression after cessation of therapy (Bonapace et al., 2014). Therefore, development of novel therapeutic concepts targeting tumor metastasis is highly warranted. Multiple pathways are implicated in the induction of endothelial permeability and TC extravasation (Reymond et al., 2013; Strilic and Offermanns, 2017), including soluble factors released from CTCs or hematopoietic cells, such as CCL2 (Wolf et al., 2012) or ATP (Schumacher et al., 2013), that act through engagement of $\mathrm{G}$ protein-coupled receptors. Certain subsets of $G$ protein-coupled receptors have been linked to activation of ADAM17 (Inoue et al., 2012).

Previous reports suggested a pivotal contribution of the TNFR superfamily (TNFRSF) members TNFR1 (Ji et al., 2014) and death receptor 6 (Strilic et al., 2016) to lymphogenic and hematogenic metastasis, respectively. TC-mediated induction of EC necroptosis via TNFRSF signaling is discussed to promote TC metastasis (Strilic et al., 2016; Hänggi et al., 2017; Hou et al., 2019; Yang et al., 2019; Patel et al., 2020), and metastasis was shown to be reduced in mice with EC-specific RIPK3 deficiency (Strilic et al., 2016; Yang et al., 2019) and in mice with kinaseinactive RIPK1 (Hänggi et al., 2017; Hou et al., 2019). However, these findings are also controversially discussed (Patel et al., 2020). Furthermore, it should be noted that i.v. injection of TCs, which is a widely used model of TC extravasation and hematogenic metastasis (Abdul Pari et al., 2021), has its limitations because it might be influenced by passive cancer cell trapping in the microvasculature or additional unknown effects.

Here, we show that hematogenic metastasis depends on TNF signaling via TNFR1 and concomitant induction of cell death in ECs. We show that during TC extravasation, TNF seems to be provided primarily by ECs. By contrast, TCs seem to exploit autocrine TNF signaling to escape from TNF-induced cell death in the circulation. It is therefore not surprising that TC-induced EC death and concomitant metastasis is impaired upon TNF neutralization.

We furthermore provide evidence that hematogenic metastasis relies on ADAM17 on ECs and that TC-induced and TNFmediated EC death is promoted by cell-autonomous ADAM17 activity. ADAM proteases, notably ADAM9 and ADAM10, were shown to accelerate necroptosis through ectodomain shedding of cell adhesion proteins (Cai et al., 2016). Furthermore, we have previously suggested that ADAM17 is involved in the induction of necroptosis (Fuchslocher Chico et al., 2018). Here, we demonstrate that TNFR1-induced cell death relies on proteolytic TNFR1 ectodomain release by ADAM17. Recently, a hexagonal arrangement of TNFR1 trimers on the plasma membrane mediated at least partially via its extracellular domains (ECDs) was proposed (Vanamee and Faustman, 2018; Vanamee and Faustman, 2020). In this model, the intracellular domains of individual TNFR1 trimers are separated largely enough to adapt 
A

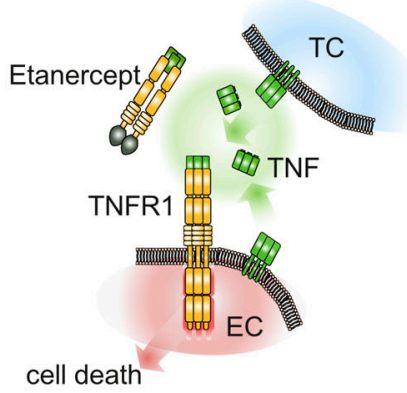

B

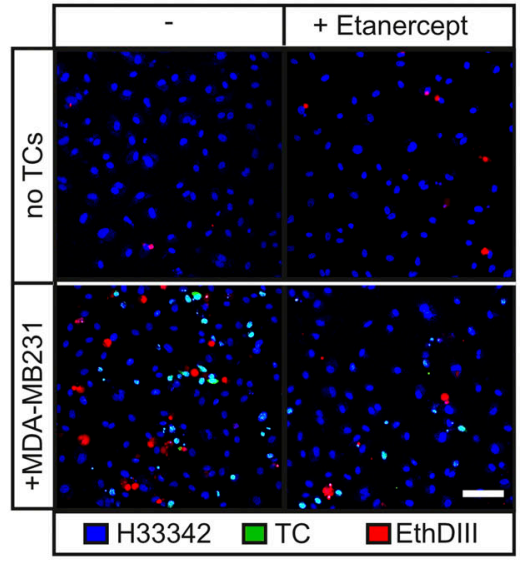

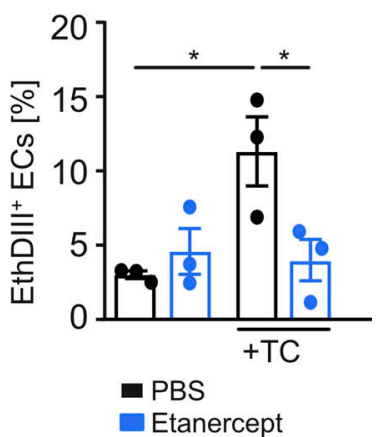

C

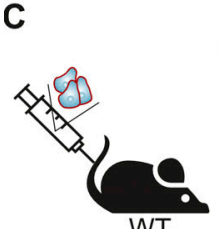

PBS,

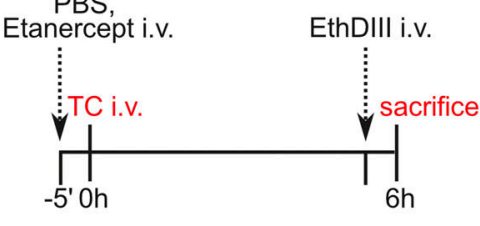

D
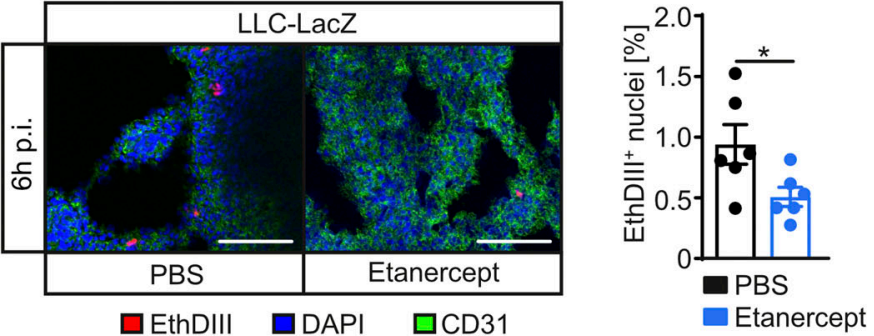

E
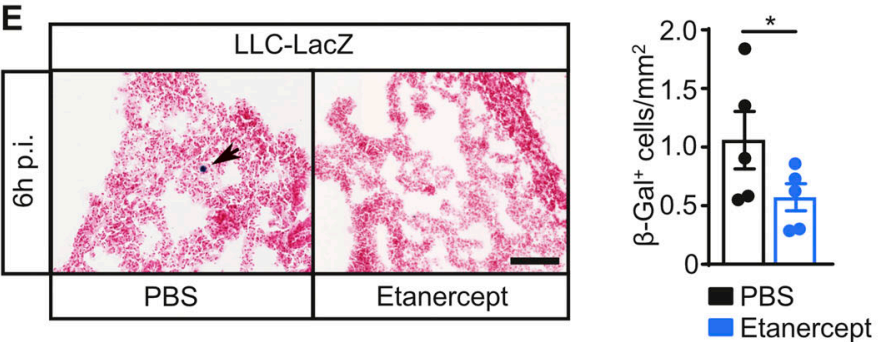

Figure 6. Pharmacological inhibition of TNF impairs TC-induced EC death and tumor extravasation. (A) Etanercept is a recombinant protein fusion of the ECD of murine TNFR2 and a human IgG Fc portion that binds to TNF and thereby blocks TNF signaling. (B) HUVECs were cocultured with CFSE-labeled MDA-MB231 TCs in the presence or absence of etanercept. Cells with impaired membrane integrity were determined after $6 \mathrm{~h}$ by EthDIII uptake and confocal microscopy. Shown are representative images of three independent experiments with three technical replicates and three to four images per replicate analyzed. Scale bar indicates $50 \mu \mathrm{m} .{ }^{*}, \mathrm{P}<0.05$ by one-way ANOVA on ranks with Dunn's post hoc test. (C) Experimental outline as performed in D and E. Where indicated, mice were injected i.v. with PBS or etanercept 5 min before TC injection. LacZ-expressing LLC TCs were i.v. injected into WT mice. 6 h later, EthDIII was i.v. injected 5 min before sacrificing where indicated. (D) Pulmonary EthDIII+ ECs were quantified from confocal images of lung sections stained for the indicated markers. Scale bar indicates $50 \mu \mathrm{m} . n=5-6$ mice/group. ${ }^{*}, P<0.05$ by unpaired two-tailed bootstrap $t$ test based on 5,000 Monte Carlo simulations. (E) Extravasated TCs $6 \mathrm{~h}$ after TC injection were quantified by $\beta$-Gal staining. Representative microscopic images are shown. Scale bar indicates $50 \mu \mathrm{m}$. $n=5-6$ mice/group. ${ }^{*}, \mathrm{P}<0.05$ by unpaired two-tailed generalized linear model based on log-Tweedie distributions. Data represent mean \pm SEM. p.i., postinjection.

a higher-order signaling complex mediated by TNFR-associated factor dimerization and trimerization interfaces (Napetschnig and $\mathrm{Wu}, 2013$; Vanamee and Faustman, 2020).

We propose that proteolytic processing of TNFR1 by ADAM17, and subsequently by the $\gamma$-secretase complex, relieves the membrane-mediated hexagonal structural constraints, thereby destabilizing the membrane-proximal receptor complex (Fig. 10 A). Subsequently, RIPK1 is liberated and upon deubiquitination, forms either the cytosolic complex IIa/b or in the presence of inactive pro-caspase-8, the RIPK1/RIPK3-containing necrosome to induce cell death via apoptosis or necroptosis, respectively. Interestingly, insertion of a tobacco etch virus protease cleavage site into the juxtamembrane region of death receptor 5 allowed for cell death induction upon tobacco etch virus proteasemediated removal of the ECD (Pan et al., 2019), suggesting that proteolytic removal of the ECD might be a general prerequisite for cell death induction by TNFRSF members.

We demonstrate that in the absence of ADAM17, levels of membrane-bound TNF increase, leading to enhanced TNFR2 engagement and subsequent noncanonical NF- $\kappa \mathrm{B}$ activation (Fig. 10 B). Therefore, ADAM17 fine-tunes TNF responses via TNFR1 and TNFR2. During metastasis, ADAM17 promotes EC death by switching TNFR1/2-mediated prosurvival signaling toward TNFR1-mediated cell death signaling. A similar role for 

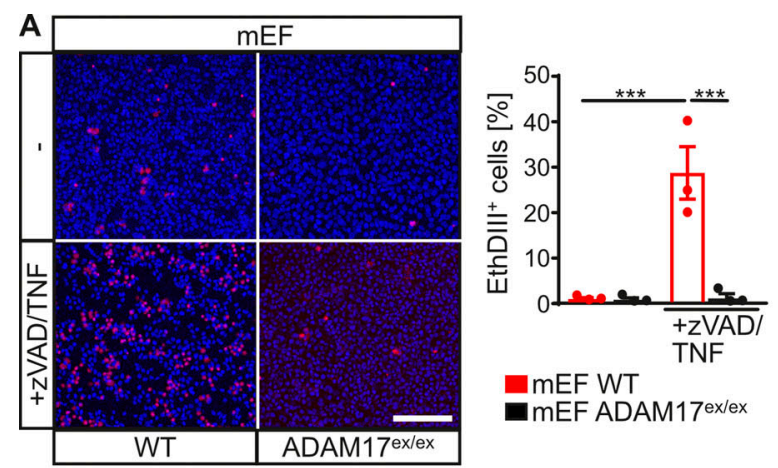

mEF WT

-mEF ADAM17ex/ex

口EthDIII घH33342
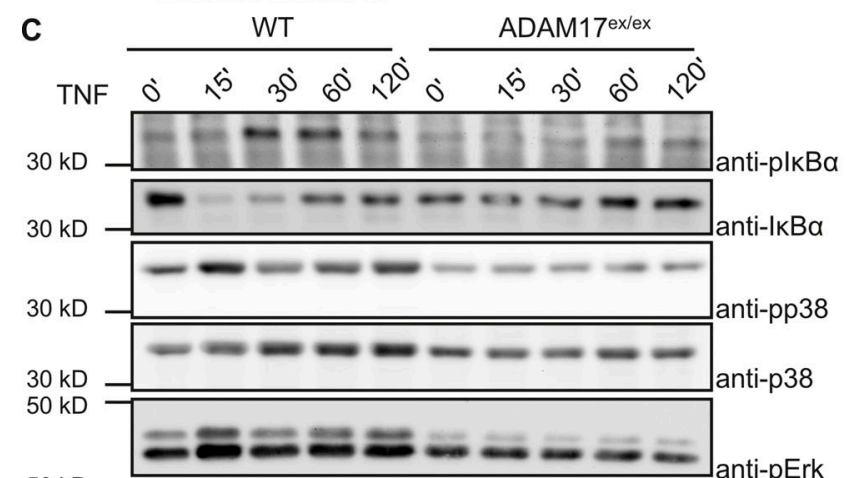

$50 \mathrm{k}$
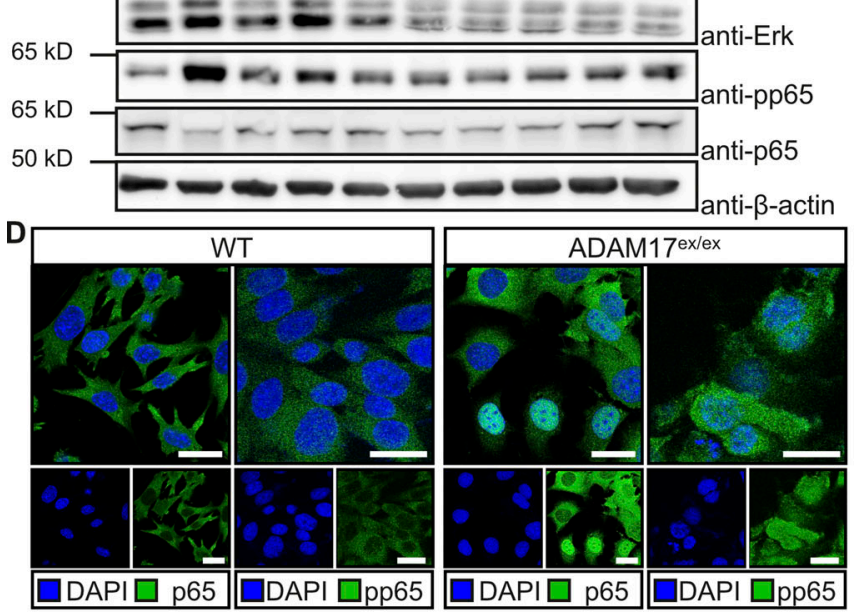

E
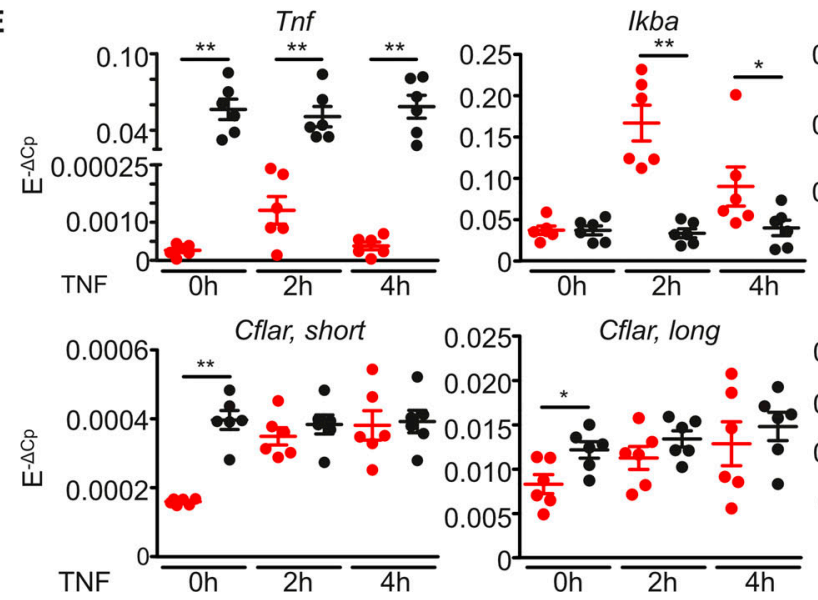
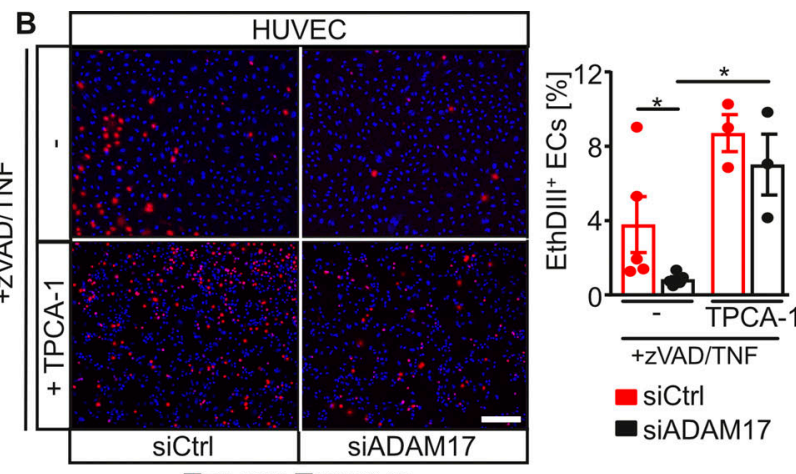

口EthDIII -H33342

pERK/ERK
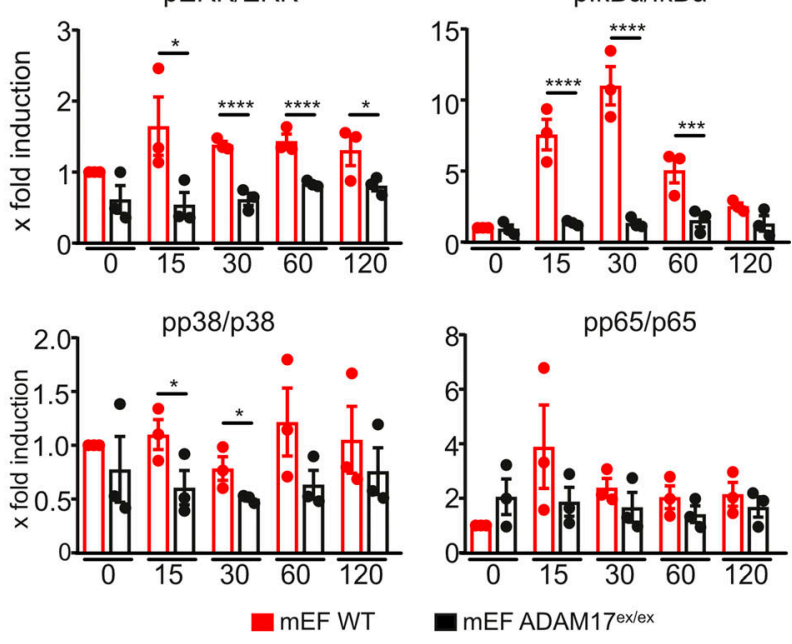

- mEF ADAM17 ex/ex

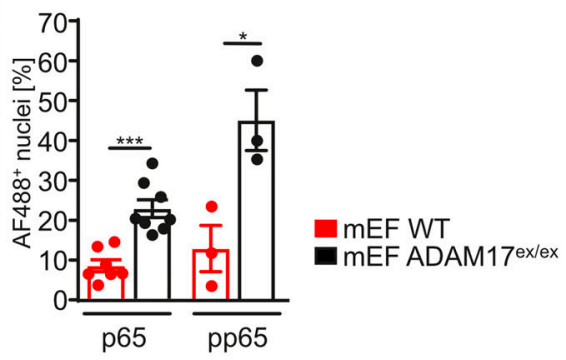

Bax 
of three independent experiments with three technical replicates per experiment and three to four images per replicate analyzed. Scale bar indicates $200 \mu \mathrm{m}$. ***, $\mathrm{P}<0.001$ by one-way ANOVA on ranks with Dunn's post hoc test. (B) HUVECs with indicated siRNA-mediated knockdown were incubated with $100 \mu \mathrm{M}$ zVAD and TPCA-1, if indicated, 15 min before stimulation with $50 \mathrm{ng} / \mathrm{ml}$ TNF. Cells with impaired membrane integrity were determined after $4 \mathrm{~h}$ by EthDIII uptake. Shown are representative images of three to five independent experiments with three technical replicates per experiment and three to four images per replicate analyzed. Scale bar indicates $200 \mu \mathrm{m}$. *, P < 0.05 by one-way ANOVA on ranks with Dunn's post hoc test. (C) mEFs with the indicated genotype were stimulated with $200 \mathrm{ng} / \mathrm{ml}$ modified tandem affinity purification-tagged TNF for the indicated time points and subsequently lysed. Cell lysates were analyzed by SDS-PAGE and immunoblotting with the indicated antibodies. Immunoblots of one representative experiment and the quantification of three independent experiments are shown. ${ }^{*}, \mathrm{P}<0.05 ;{ }^{* *}, \mathrm{P}<0.001 ;{ }^{* * *}, \mathrm{P}<0.0001$ by generalized estimating equation models with least significant difference post hoc tests with Bonferroni corrections. (D) mEFs with the indicated genotype were grown on coverslips, and phosphorylation and nuclear translocation of the NF- $\mathrm{B}$ component $\mathrm{p} 65$ was determined by immunofluorescence and confocal microscope. Shown are representative microscopic images and the quantification of nuclear signals from eight (p65) or three (pp65) independent experiments. Scale bars indicate $25 \mu \mathrm{m} .{ }^{*}, \mathrm{P}<0.05 ;{ }^{* *}, \mathrm{P}<0.001$ by unpaired two-tailed bootstrap $t$ test. (E) mEFs with the indicated genotype were stimulated with $200 \mathrm{ng} / \mathrm{ml}$ TNF for the indicated time points, and expression of the indicated NF-

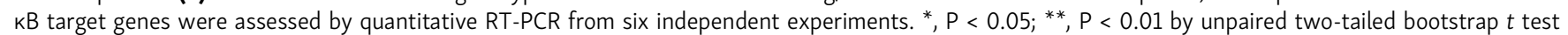
based on 5,000 Monte Carlo simulations. Data represent mean \pm SEM. Ctrl, control.

ADAM17 in regulating a TNFR1-to-TNFR2 balance might be involved in atherosclerosis (Nicolaou et al., 2017) and liver fibrosis (Sundaram et al., 2019).

There is compelling evidence that expression of ADAM17 on TCs provides protumorigenic signals, e.g., by the release of EGFR ligands (Murphy, 2008). We recently demonstrated that ADAM17 activity on tumor-associated macrophages is needed to promote intestinal tumorigenesis via IL-6 transsignaling (Schmidt et al., 2018). Furthermore, diagnostic or therapeutic manipulation of primary tumors by fine-needle biopsy, tumor irradiation, or tumor surgery were associated with an increase in CTCs and with an increased risk of metastasis (Martin et al., 2017). This might be, at least in part, a result of the induction of a local inflammatory response with increased release of inflammatory cytokines, likely involving the proteolytic activity of ADAM17. Inhibition of ADAM17 as adjuvant therapy in patients with advanced-stage cancer might therefore lower the risk of metastasis. We indeed observed that ADAM17 is strongly expressed on ECs in lungs of patients suffering from pulmonary metastatic spread of different solid tumors, suggesting that activation of endothelial ADAM17 is a general phenomenon during metastasis (Fig. S1 C).

Using recombinant inhibitory ADAM17 PD, we present here a novel therapeutic concept to prevent metastatic seeding. ADAM17 PD shares almost no homology with other PDs of the ADAM or matrix metalloproteinase family, making it a suitable candidate for specific ADAM17 inhibition (Wong et al., 2016). While many antitumor agents suppress growth of the primary tumor, they enhance metastatic seeding. Inhibition of ADAM17 with the highly specific ADAM17 PD might therefore be superior to previous treatment regimen, as it inhibits both growth of the primary tumor (Schmidt et al., 2018) and metastatic seeding. Future development of recombinant ADAM17 PD for the treatment of advanced-stage cancer is therefore highly warranted. Taken together, we identified the transmembrane metalloprotease ADAM17 as a novel key player of cellular necroptosis and as a promising target for the prevention of tumor metastasis.

\section{Materials and methods}

\section{Compounds, antibodies, and reagents}

PBS (\#D8537), Hoechst 33342, and FITC-labeled 40-kD dextran (\#FD40S) were purchased from Sigma-Aldrich. TAPI-1 (\#BMLPI134) was from Enzo Life Sciences. EthDIII (\#B-40050) was from Biotium/Hölzel Diagnostika. TNFR1 (\#DY-425) ELISAs were from R\&D Systems. CFSE was from eBiosciences. zVADfmk (\#N-1510) was from Bachem. TPCA-1 (\#Cay-15115) was from Biomol/Cayman Chemical. Human and mouse TNF was purchased from ImmunoTools.

\section{Cell lines and reagents}

LLC and B16F1 cells were from Cell Lines Service. MDA-MB231 were provided by Dr. Nina Hedemann (University Hospital Kiel, Kiel, Germany). HUVECs were from PromoCell. HMVEC-L were from Lonza. LLC-LacZ, B16F1-LacZ, ADAM17-deficient HEK293T cells, ADAM17 ${ }^{\text {ex/ex }} \mathrm{mEFs}$, and PSEN1 ${ }^{+/-} / 2^{-/-} \mathrm{mEFs}$ were described previously (Tournoy et al., 2004; Chalaris et al., 2010; Riethmueller et al., 2016). TNF $^{-/-}$mEFs (Peltzer et al., 2014) and TNFR1 ${ }^{-1-}$ mEFs (Pfeffer et al., 1993) were described previously. HUVECs and HMVEC-L were cultivated in EGM-2 (\#C-22011; PromoCell) and EGM-MV2 (\#C-2212; PromoCell), respectively. All other cell lines were cultivated in DMEM $+10 \%$ FCS. All cells were incubated at $37^{\circ} \mathrm{C}, 5 \% \mathrm{CO}_{2}$ and $95 \%$ humidity. Cell lines were tested routinely at least every 3 mo for Mycoplasma contamination by PCR. For more detailed information on cell lines or reagents, see supplemental tables.

\section{Generation of TNF-deficient murine TCs}

Murine TC lines B16F1-LacZ and LLC-LacZ were transfected with single guide RNAs (sgRNAs; Table S4) and recombinant Cas9 using the Neon electroporation device (Thermo Fisher Scientific) according to manufacturer's instructions. For detailed settings, see Table S5. Cells were subsequently plated in fresh culture medium. After $3 \mathrm{~d}$, single-cell suspensions were seeded. Single-cell clones and the polyclonal pool were analyzed by PCRbased genotyping. In brief, genomic DNA was isolated using GeneJET Genomic DNA isolation kit (Thermo Fisher Scientific), and exon 5 was PCR amplified. PCR amplicons were excised, gel extracted using GeneJET Gel Extraction Kit (Thermo Fisher Scientific), and verified by Sanger sequencing.

\section{Isolation of primary murine lung ECs}

Tamoxifen-injected Cdh5-CreERT2::ADAM17flox/flox or control mice were sacrificed, and lungs were first manually cut into small pieces and further subjected to digestion by collagenase type II (STEMCELL Technologies) for $30 \mathrm{~min}$ at $37^{\circ} \mathrm{C}$ in a shaking water bath. After $15 \mathrm{~min}$ and at the end of the digestion, tissue was passed through a $21 \mathrm{G}$ syringe. The digestion was stopped 
A

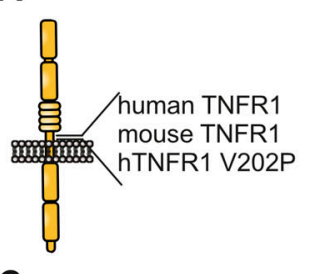

C

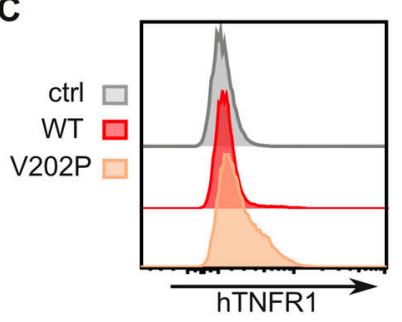

ADAM17

$\dddot{*}$

200 TM domain

DSGTT VLLPLV.

${ }^{201}$ AN: VTNPQDSSGTA VLLPLV...

... ${ }^{200}$ EN PKGTEDSGTT VLLPLV...

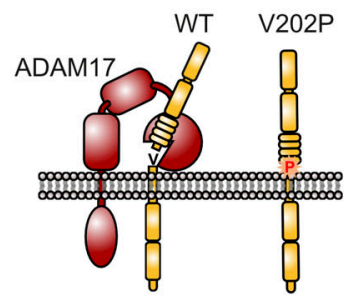

D

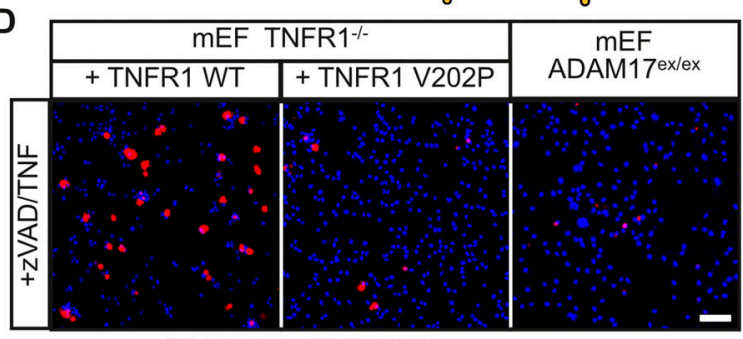

口H33342 口EthDIII
B
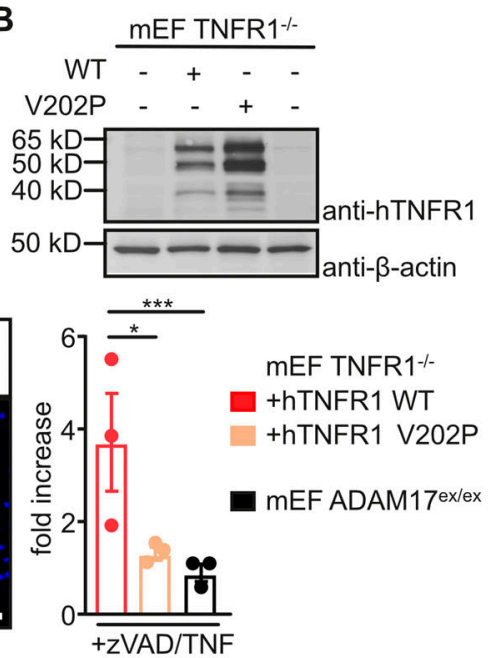

E
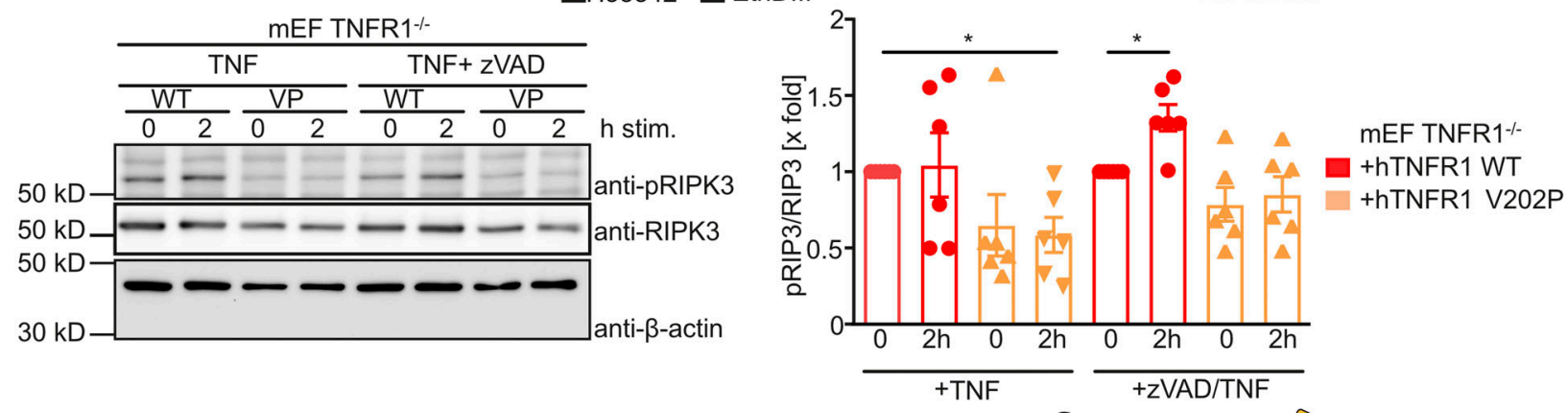

$\mathbf{F}_{\text {mEF }} \quad$ WT ADAM17 exlex
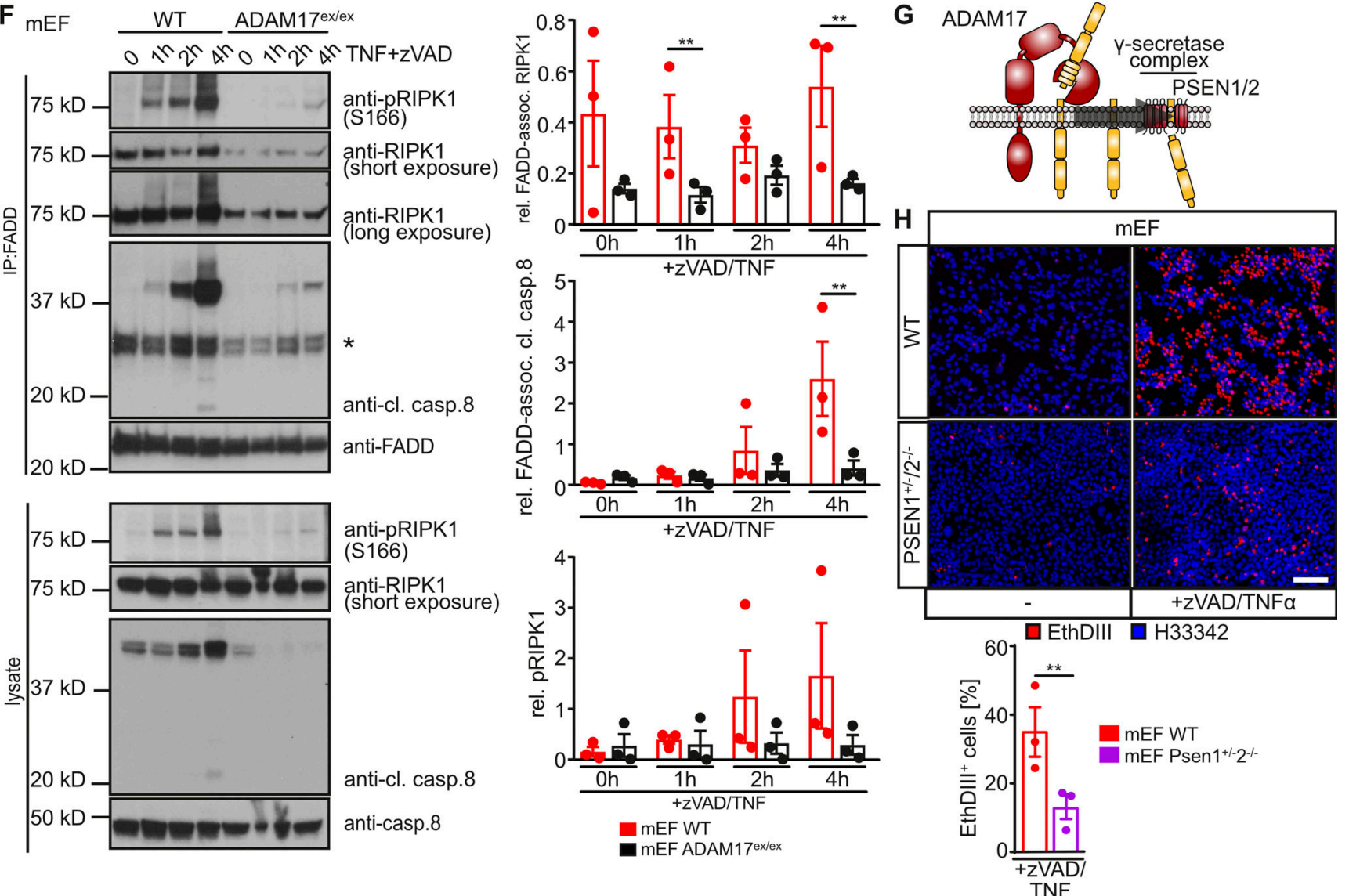

Figure 8. Proteolytic processing of TNFR1 by ADAM17 and $\mathrm{y}$-secretase enables cell death induction. (A) Amino acid sequence around the ADAM17 cleavage site in human and murine TNFR1. Substitution of the P1' valine to proline in the cleavage-resistant TNFR1 V202P variant is indicated in red. 
(B) TNFR1 ${ }^{-/-}$mEFs were retrovirally reconstituted with the indicated FLAG-hTNFR1 variants, and expression was verified by SDS-PAGE and immunoblotting using the indicated antibodies. (C) Cell surface levels of the indicated FLAG-hTNFR1 variants stably expressed in TNFR1 ${ }^{-/-}$mEFs were determined by flow cytometry using anti-TNFR1 antibodies; ctrl (control) indicates unstained cells. (D) TNFR1 ${ }^{-1}$ mEFs reconstituted with the indicated TNFR1 variants or ADAM17 $7^{\text {ex ex }} \mathrm{mEFs}$ were incubated with $100 \mu \mathrm{M}$ zVAD 15 min before stimulation with $50 \mathrm{ng} / \mathrm{ml}$ TNF. Cells with impaired membrane integrity were detected by EthDIII uptake after $4 \mathrm{~h}$. Shown are representative images and the quantification of three independent experiments with three replicates and three to four images per replicate analyzed. Scale bar indicates $50 \mu \mathrm{m}$. ${ }^{*}, \mathrm{P}<0.05 ;{ }^{* *}, \mathrm{P}<0.001$ by generalized estimating equation model. (E) TNFR1 ${ }^{-/-} \mathrm{mEFs}$ reconstituted with the indicated TNFR1 variants were incubated with $100 \mu \mathrm{M} \mathrm{zVAD}$ or mock-treated 15 min before stimulation with $50 \mathrm{ng} / \mathrm{ml}$ TNF for $2 \mathrm{~h}$. Cells were subsequently lysed, and lysates were analyzed by SDS-PAGE and immunoblotting using the indicated antibodies. One representative immunoblot and the quantification of five independent experiments are shown. ${ }^{*}, \mathrm{P}<0.05$ by generalized estimating equation model. (F) WT or ADAM17 ex/ex mEFs were incubated with $100 \mu \mathrm{M}$ zVAD $15 \mathrm{~min}$ before stimulation with $1 \mu \mathrm{g} / \mathrm{ml}$ TNF for the indicated time points and subsequently lysed. FADD was isolated by immunoprecipitation, and coassociated proteins were identified by SDS-PAGE and immunoblotting using the indicated antibodies. One representative immunoblot and the quantification of three independent experiments are shown. Asterisk indicates Ig light chains. ${ }^{* *}, \mathrm{P}<0.01$ by generalized estimation equation model. (G) TNFR1 ectodomain shedding by ADAM17 might be followed by intramembrane proteolysis mediated by the PSEN-containing $\mathrm{Y}$-secretase complex, which would result in the liberation of a C-terminal TNFR1 fragment. (H) mEFs with the indicated genotype were incubated with $100 \mu M$ zVAD 15 min before stimulation with $50 \mathrm{ng} / \mathrm{ml}$ TNF. Cells with impaired membrane integrity were detected by EthDIII uptake after $4 \mathrm{~h}$. Shown are representative images and the quantification of three independent experiments with three technical replicates per experiment and three to four images per replicate analyzed. ${ }^{* *}, \mathrm{P}<0.01 ;$ unpaired twotailed Student's $t$ test. Data represent mean \pm SEM. assoc. associated; cl. casp.8, cleaved caspase 8; IP, immunoprecipitation; rel., relative; stim., stimulated; TM, transmembrane; VP, V202P.

with DMEM plus $10 \%$ FCS, and cells were further filtered through cell strainers $(100 \mu \mathrm{m}, 70 \mu \mathrm{m}, 40 \mu \mathrm{m})$. The resulting cell suspension was centrifuged $\left(500 \mathrm{~g}, 5 \mathrm{~min}, 4^{\circ} \mathrm{C}\right)$ twice. The pellets were combined and washed in PBS. Cells were treated with Fc-block in MACS buffer (0.5\% BSA, 2 mM EDTA in PBS without $\mathrm{Ca}^{2+}$ ) and further stained with anti-CD31-FITC, anti-CD45-PE, and anti-Terrl19-PE for $30 \mathrm{~min}$, shaking at room temperature (for detailed antibody usage see Table S2). Depletion of $\mathrm{PE}^{+}$cells was performed with anti-PE magnetic beads and LD columns according to the manufacturer's instructions. Subsequently, the PE-depleted suspension was subjected to positive selection of FITC $^{+}$cells with anti-FITC magnetic beads and LS columns (see Table S1 for further details). The PE', PE-FITC double-negative, and FITC $^{+}$fractions were collected, and purity was determined by flow cytometry on a FACSCanto II system. Samples were lysed in radioimmunoprecipitation assay buffer and boiled for 5 min with $5 \times$ Laemmli buffer. SDS-PAGE and immunoblot analysis followed as described above.

\section{Animal models}

$\mathrm{RIPK}^{-1-}$ mice were originally obtained from Genentech (Newton et al., 2004). Hypomorphic ADAM17 (ADAM17ex/ex; Chalaris et al., 2010; Schmidt et al., 2018) and TNFR1 ${ }^{-1-}$ mice (Pfeffer et al., 1993) have been described previously. LysM-Cre:: ADAM17 flox/flox (ADAM17 ${ }^{\triangle M C}$ ) and Cdh5-CreERT2::ADAM17 flox/flox (ADAM17 ${ }^{\mathrm{I} E \mathrm{EC}}$ ) mice were homozygous for the floxed ADAM17 allele (Horiuchi et al., 2007) and heterozygous for the Cre recombinase under the control of the lysozyme M (Clausen et al., 1999) and the tamoxifen-inducible cadherin 5 promoter (Sörensen et al., 2009), respectively. Cdh5-CreERT2:: ADAM17flox/flox mice were injected i.p. with $25 \mathrm{mg} / \mathrm{kg}$ body weight (BW) 4-OH-tamoxifen (Sigma-Aldrich) in EtOH/oil, for $4 \mathrm{~d}$ consecutively to induce recombination of the floxed ADAM17 exon 2. Control mice received the same amount of injections with EtOH/oil only. All mice were bred on a C57BL/6 background and housed under controlled conditions (specific pathogen free, $22^{\circ} \mathrm{C}, 12$-h day-night cycle) and fed standard laboratory chow ad libitum. Animal experiments were conducted according to national and European animal regulations and have been approved by Department of Consumer Protection and Veterinary Affairs at the Ministry of Energy, Agriculture, the Environment, Nature and Digitalization of the Schleswig Holstein State Government (V242-74639/2016 [75-6/15], V24365407/2015 [75-6/11], V242-70603/2017 [53-5/16]).

\section{Human living donor samples}

Tissue specimen of human pulmonary metastases and adjacent peritumoral tissue derived from either primary colorectal or renal cell carcinoma were supplied by the Kiel Biomaterial Bank of the Comprehensive Cancer Center, University Medical Center Schleswig-Holstein. Informed written consent was obtained from the patients, and the sample collection and analyses in this study were approved by the ethics committee of the Medical Faculty of Kiel University (Ref. No. $110 / 99)$.

\section{Metastasis model}

$5 \times 10^{5}$ LLC or B16F1 cells in $250 \mu$ l sterile PBS (\#D8537; SigmaAldrich) were injected i.v. into the lateral tail vein. For inhibitory experiments, TAPI-1 or ADAM17 PD were injected i.v. 5 min before TC injection. ADAM17 PD and TAPI-1 were injected at a concentration of $1 \mathrm{mg} / \mathrm{kg}$ BW and $12 \mathrm{mg} / \mathrm{kg}$ BW, respectively. To assess endothelial permeability, mice were injected with $200 \mu \mathrm{l}$ $2.5 \mathrm{mg} / \mathrm{ml}$ FITC-labeled 40-kD dextran (\#FD40S; Sigma-Aldrich) $10 \mathrm{~min}$ before sacrificing.

For the identification of necroptotic ECs, EthDIII (\#B-40050; Biotium/Hölzel Diagnostika) was injected i.v. at a concentration of $300 \mu \mathrm{M}$ (in $50 \mu \mathrm{l}$ PBS) 5 min before sacrificing the mice.

\section{Immunohistochemistry and immunofluorescence}

Tissue specimens of human pulmonary metastases and adjacent peritumoral tissue derived from either primary colorectal or renal cell carcinoma were obtained from patients' fresh, unfixed surgical resectates; split by pathologists into tumor tissue and peritumoral nonmalignant tissue; and snap frozen in liquid $\mathrm{N}_{2}$ and stored at the biobank at $-80^{\circ} \mathrm{C}$.

Murine tissue specimens were snap frozen in optimal cutting temperature (OCT) Tissue-Tek compound (Plano GmbH) and cut 


\section{\%JEM}

A
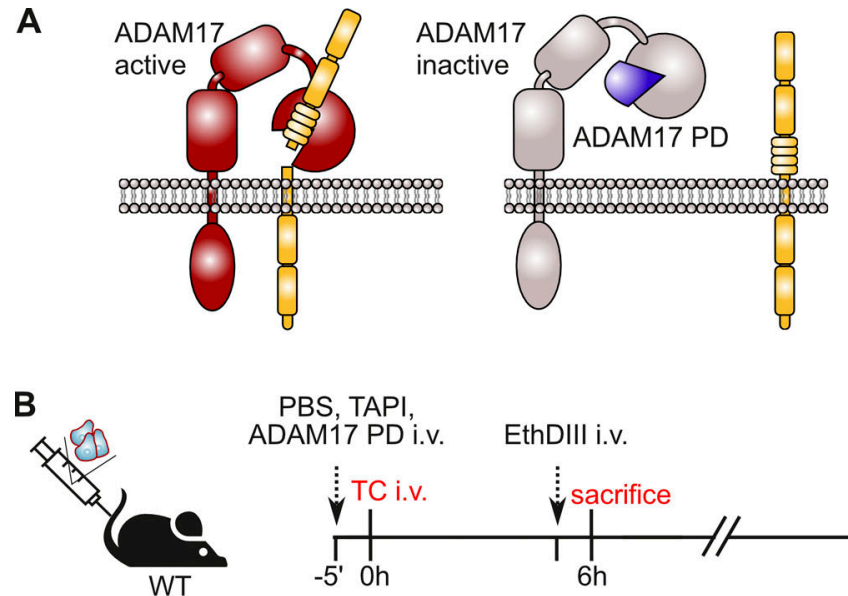

PBS, TAPI, ADAM17 PD i.v.

EthDIII i.v.
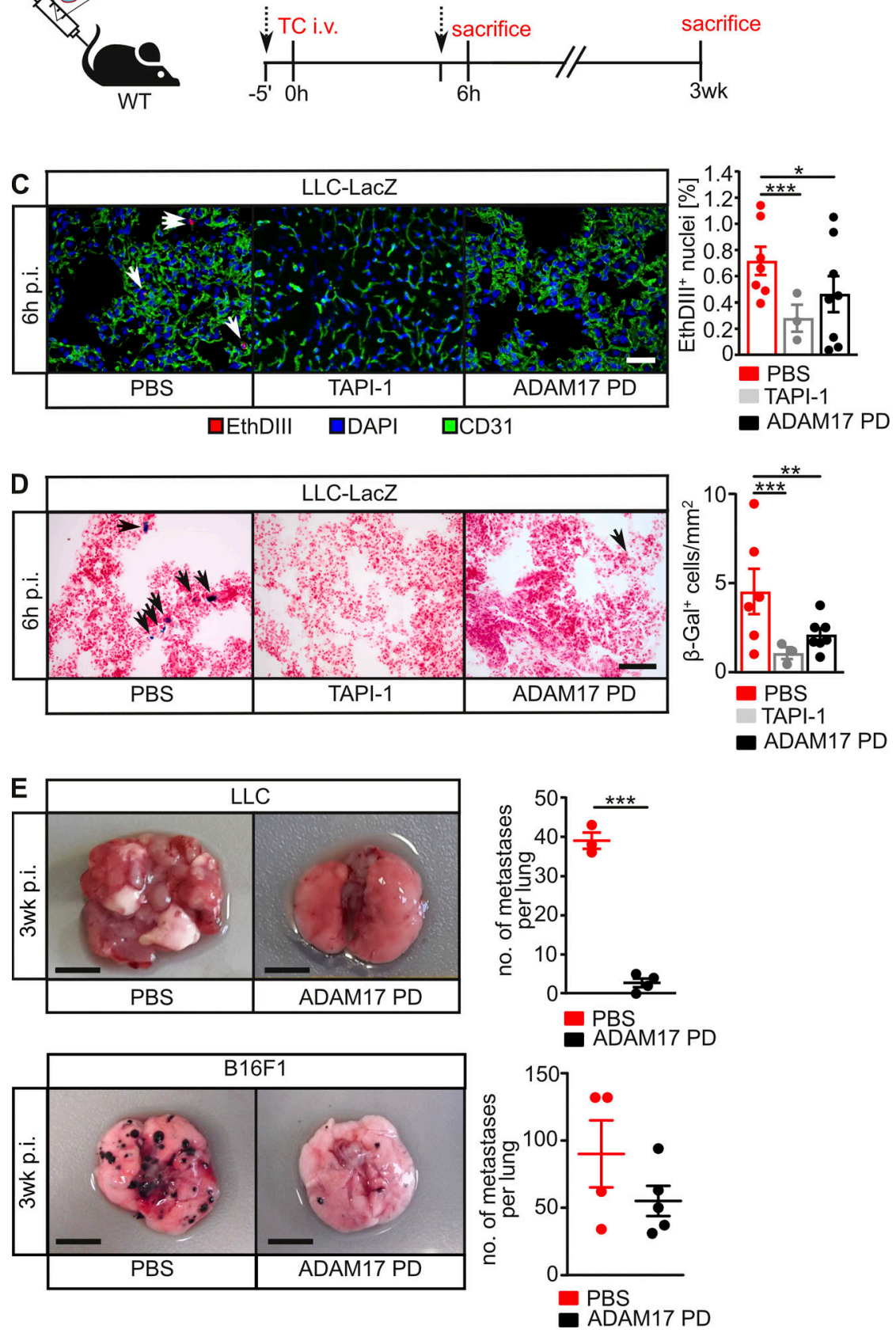

Figure 9. Pharmacological inhibition of ADAM17 prevents metastasis to the lung. (A) Schematic of ADAM17 PD-mediated inhibition of ADAM17. (B) Experimental outline as performed in C-E. WT animals were i.v. injected with $12 \mathrm{mg} / \mathrm{kg}$ BW TAPI-1 or $1 \mathrm{mg} / \mathrm{kg}$ BW ADAM17 PD 10 min before i.v. injection with $5 \times$ $10^{5}$ parental LLC or B16F1 TCs (E) or LacZ-expressing LLC TCs (C and D). 6 h later, EthDIII was i.v. injected 10 min before sacrificing (C); extravasated TCs were quantified by $\beta$-Gal staining (D); and $21 \mathrm{~d}$ after injection, lung metastases were determined (E). (C) Confocal images of lung sections $6 \mathrm{~h}$ after TC injection, stained for the indicated markers. Scale bar indicates $100 \mu \mathrm{m} . n=6-7$ mice/group (PBS), $n=3$ mice/group (TAPI), and $n=8$ mice/group (ADAM17 PD). ${ }^{*}, \mathrm{P}<$ $0.05 ;{ }^{* *}, \mathrm{P}<0.001$; one-way ANOVA on ranks with Dunn's post hoc test. (D) Representative microscopic images $6 \mathrm{~h}$ after TC injection. Scale bar indicates 50 $\mu \mathrm{m} . n=6-7$ mice/group (PBS), $n=3$ mice/group (TAPI), and $n=8$ mice/group (ADAM17 PD). ${ }^{* *}, P<$ $0.01 ;{ }^{* * *}, \mathrm{P}<0.001$; one-way ANOVA on ranks with Dunn's post hoc test. (E) Lung images $21 \mathrm{~d}$ after TC injection are shown. Scale bar indicates $5 \mathrm{~mm} . n=3-5$ mice/group. ${ }^{* * *}, \mathrm{P}<0.001$; unpaired two-tailed Student's $t$ test. Data are mean \pm SEM. p.i., postinjection. into 8 - $\mu \mathrm{m}$-thick sections. Frozen human tissue specimens were embedded in OCT Tissue-Tek compound and cut into $8-\mu \mathrm{m}$-thick sections. Sections were fixed in acetone:methanol (1:1 vol/vol) for $2 \mathrm{~min}$ and subjected to immunofluorescent staining according to standard procedures. Antibody specifications are listed in Table S2. LacZ-expressing cells were identified in frozen tissue sections by $\beta$-Gal enzymatic assay. 
A

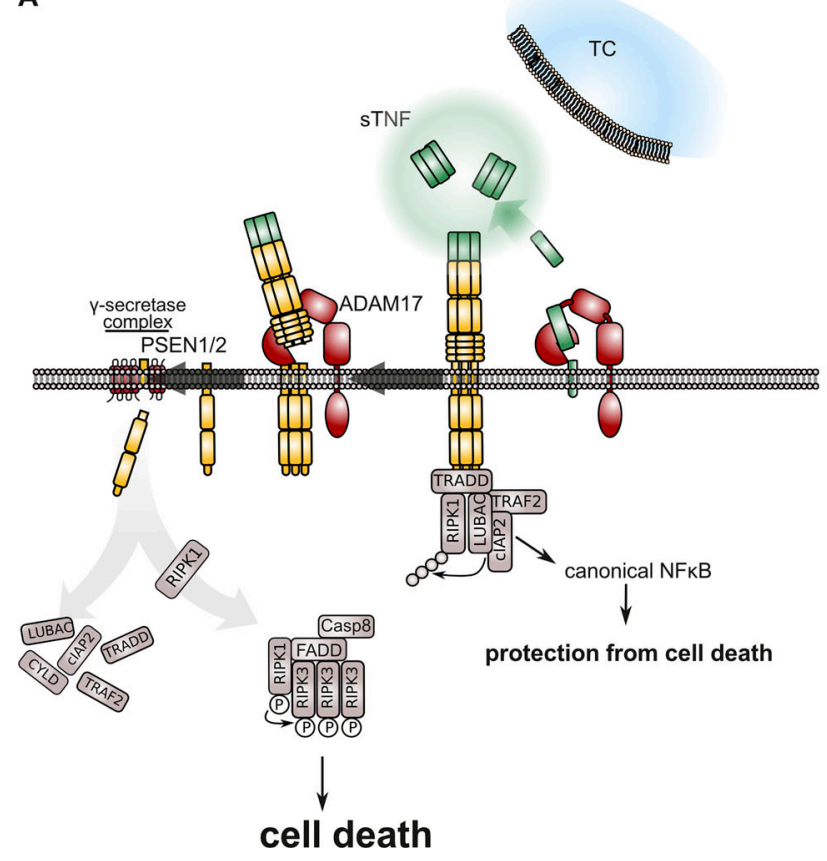

B

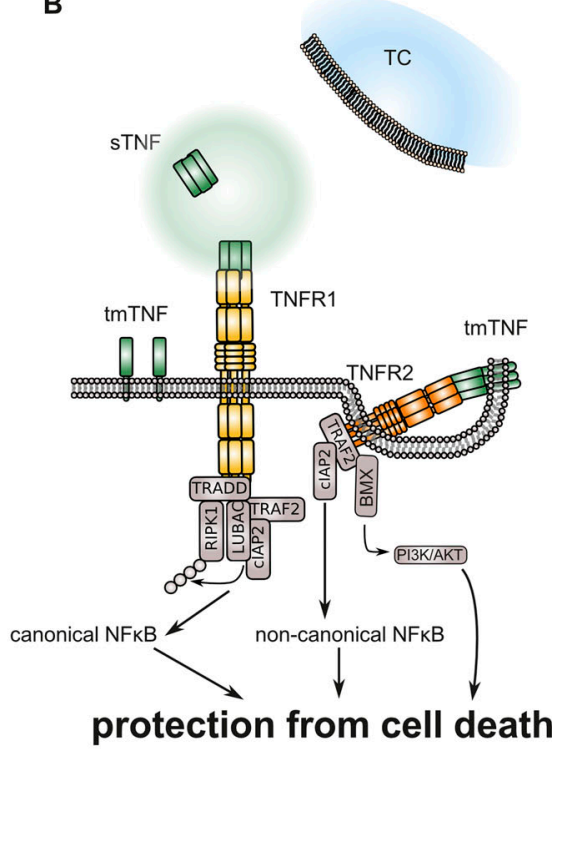

Figure 10. Model of ADAM17-mediated TNFR1-dependent EC death during TC extravasation. (A) Interaction of TCs with ECs induces endothelial TNF secretion. Soluble TNF (sTNF) might also be provided by inflammatory cells, such as T cells. Engagement of TNFR1 is followed by ADAM17-mediated ectodomain cleavage. The TNFR1 membrane stub is further subjected to intramembrane proteolysis PSEN1/2. Proteolytic processing of TNFR1 enables dissociation of TNFR1 complex I, assembly of complex II or the necrosome, and induction of EC death. (B) In the absence of endothelial ADAM17 or if ADAM17 enzymatic activity is inhibited, TNFR1 signaling is restricted to complex I formation and prosurvival signaling via canonical NF-kB activation. Furthermore, accumulation of transmembrane TNF (tmTNF) enhances TNFR2 signaling and activation of noncanonical NF-kB signaling. Consequently, ECs are protected from TNF-induced cell death.

\section{Flow cytometry}

Murine LLC-LacZ and B16F1-LacZ cells were stimulated with 100 nM PMA, $1.3 \mu \mathrm{M}$ ionomycin, and $10 \mu \mathrm{M}$ brefeldin A for $4 \mathrm{~h}$ at $37^{\circ} \mathrm{C}$. Subsequently, cells were trypsinized and fixed in $3.7 \%$ paraformaldehyde for $10 \mathrm{~min}$ at $37^{\circ} \mathrm{C}$. Washed cells were permeabilized in $90 \%$ methanol on ice for $30 \mathrm{~min}$ and after washing, stained with a-TNF-a-APC (\#17-7321-81, clone MP6$\mathrm{XT22}$, 1:80; eBioscience) or isotype control for $1 \mathrm{~h}$ at room temperature in the dark.

Human MDA-MB231 cells were detached with citrate buffer (135 mM KCl, $15 \mathrm{mM}$ sodium citrate), washed in PBS, and blocked with $10 \%$ FCS in $1 \%$ BSA in PBS for 10 min on ice. Subsequently, membrane-bound TNF- $\alpha$ was stained with primary antibody a-TNF- $\alpha$ (1:16; R\&D Systems) for $1 \mathrm{~h}$ on ice and with secondary anti-goat-AF488 (A11055, 1:200; Life Technologies) for 30 min on ice in the dark. All samples were acquired in $1 \%$ BSA in PBS on a FACSCanto II system and analyzed with FlowJo version 10.06 software.

\section{mRNA isolation and quantitative RT-PCR}

Activation of NF- $\kappa$ B-dependent genes upon TNF stimulation in ADAM17ex/ex mEFs and control mEFs was analyzed in $5 \times 10^{5}$ cells per condition. For mRNA isolation and quantitative PCR, $16 \mathrm{~h}$ after seeding, cells were stimulated with $200 \mathrm{ng} / \mathrm{ml} \mathrm{TNF}$ in DMEM without serum for the indicated time points. Cells were subsequently washed in PBS, and RNA was isolated with the NucleoSpin RNA Kit according to the manufacturer's instructions. $1 \mu \mathrm{g}$ of RNA was used for cDNA synthesis using oligo- $(\mathrm{dT})_{18}$ primers and RevertAid Reverse Transcription Kit (\#EP0441; Thermo Fisher Scientific) according to the manufacturer's instructions. Data of the quantitative PCR were acquired on a Roche LightCycler 480 using Roche Universal Probes.

\section{$\beta$-Gal staining and analysis}

Lung tissue was snap frozen in OCT Tissue-Tek compound and cut into $8-\mu \mathrm{m}$-thick sections. Sections were fixed in $0.2 \%$ glutaraldehyde for $10 \mathrm{~min}$ at $4^{\circ} \mathrm{C}$. Slides were then washed three times in $\mathrm{LacZ}$ washing buffer (PBS, $2 \mathrm{mM} \mathrm{MgCl}_{2}, 0.01 \%$ sodium deoxycholate, $0.02 \% \mathrm{NP}-40$ ) at room temperature. Subsequently, sections were circled with a PAP pen (DAKO) and incubated at $37^{\circ} \mathrm{C}$ overnight with staining solution $(5 \mathrm{mM}$ $\mathrm{K}_{3} \mathrm{Fe}(\mathrm{CN})_{6}, 5 \mathrm{mM} \mathrm{K}_{4} \mathrm{Fe}(\mathrm{CN})_{6}, 0.5 \mathrm{mg} / \mathrm{ml} \mathrm{X-Gal} \mathrm{in} \mathrm{LacZ} \mathrm{washing}$ buffer) in a humidified chamber. The next day, slides were washed for $5 \mathrm{~min}$ in PBS and double-distilled $\mathrm{H}_{2} \mathrm{O}$, respectively. Sections were counterstained with Nuclear Fast Red (SigmaAldrich) according to manufacturer's instructions and mounted with Histokitt II (Carl Roth). Tissue sections were imaged with a Hamamatsu NanoZoomer digital slide scanner, and $\beta-\mathrm{Gal}^{+}$cells on the complete section were quantified using ImageJ.

\section{TNFR1 complex II isolation}

For TNFR1 complex II isolation, $10^{7}$ control or ADAM17 ex/ex mEFs were starved overnight and stimulated the next day with $20 \mu \mathrm{M}$ 
zVAD and $1 \mu \mathrm{g} / \mathrm{ml}$ TNF for the indicated time periods. zVAD was administered $15 \mathrm{~min}$ before TNF. Stimulation was stopped by removal of medium. Cells were lysed in coimmunoprecipitation buffer (50 mM Hepes, 150 mM HCl, 1 mM EDTA, 2 mM EGTA, $10 \%$ glycerol, $0.5 \% \mathrm{NP}-40,2 \mathrm{mM} \mathrm{KCl}$ ) supplemented with protease and phosphatase inhibitors (\#11836170001, \#4906837001; Roche). Removed medium with stimulus was centrifuged (1,400 rpm for $3 \mathrm{~min})$, and pellets of dying cells were combined with cell lysates. Lysates were cleared by centrifugation and concentrations adjusted. For immunoprecipitation, protein G agarose (\#16-266; Millipore) was washed in HNGT buffer (20 mM Hepes, 150 mM NaCl, 10\% glycerol, 0.1\% Triton X-100) and incubated with a-FADD antibody $(1.4 \mu \mathrm{g} /$ time point, G-4, \#Sc-271748; Santa Cruz Biotechnology) for $2 \mathrm{~h}$ rolling at room temperature. Prepared beads were subsequently incubated with 1-2 mg of protein lysate, rolling overnight at $4^{\circ} \mathrm{C}$. The next day, beads were washed with HNGT buffer supplemented with protease and phosphatase inhibitors and heated to $60^{\circ} \mathrm{C}$ for $30 \mathrm{~min}$ with $2 \times$ reducing Laemmli buffer. Immunoprecipitates and untreated lysates were analyzed by SDS-PAGE and immunoblotting as described above.

\section{Immunoblotting}

Where indicated, cells were starved overnight in DMEM without serum before stimulation with $200 \mathrm{ng} / \mathrm{ml}$ TNF for the indicated time periods. Samples were lysed in radioimmunoprecipitation buffer (50 mM Hepes, pH 7.4, 150 mM NaCl, 1 mM EDTA, 2 mM EGTA, 0.5\% NP-40) supplied with $50 \mathrm{mM} \mathrm{NaF}$ and protease and phosphatase inhibitors. Proteins were separated by electrophoresis on $10 \%$ SDS gels and transferred to polyvinylidenfluoride membranes. Membranes were incubated with primary antibodies overnight at $4^{\circ} \mathrm{C}$ and with horseradish peroxidaseconjugated secondary antibodies at room temperature for $30 \mathrm{~min}$. An enhanced chemiluminescence substrate kit (Thermo Fisher Scientific) was used for detection.

\section{ELISA}

Mouse TNFR1 (\#DY425), human TNFR1 (\#DY225), mouse TNF (\#DY410), and human TNF (\#DY210) (R\&D Systems) ELISAs were performed according to the manufacturer's instructions.

\section{Transmigration assays}

HUVECs or HMVEC-L were cultured for $2 \mathrm{~d}$ and subsequently seeded at $5 \times 10^{4}$ into collagen I-coated 24-well inserts with a pore diameter of $8 \mu \mathrm{m}$ (Sarstedt). On the next day, ECs were transfected twice with 2 pmol siRNA (Table S3) using Lipofectamine RNAiMAX (Thermo Fisher Scientific) on 2 consecutive days. For the transendothelial migration experiments, $5 \times$ $10^{3}$ MDA-MB231 cells were stained with $8 \mu \mathrm{M}$ CFSE and seeded on top of the ECs. Transmigrated cells that passed the membrane were imaged $6 \mathrm{~h}$ later on a Leica DMi8 inverted fluorescent microscope and quantified using ImageJ.

\section{In vitro cell death assays}

To assess cell death in vitro, $10^{4}$ HUVECs were seeded in collagen I-coated lumox 96-well plates (Sarstedt). Subsequently, cells were transfected twice with 2 pmol siRNA/well (Table S2) using
Lipofectamine RNAiMAX (Thermo Fisher Scientific) on 2 consecutive days. For coculture experiments, $1.5 \times 10^{3}$ MDA-MB231 cells were stained with $8 \mu \mathrm{M}$ CFSE (Thermo Fisher Scientific) and seeded on top of the ECs in endothelial growth medium. To trigger cell death independent of TCs, ECs or mEFs were treated with $100 \mu \mathrm{M}$ zVAD-fmk (\#N-1510; Bachem) either alone or together with $5 \mu$ M TPCA-1 (\#Cay-15115; Biomol/Cayman Chemical) $10 \mathrm{~min}$ before TNF (50 ng/ml; ImmunoTools) stimulation. After incubation for $6 \mathrm{~h}$, the cells were stained with $2 \mu \mathrm{M}$ Hoechst 33342 (Sigma-Aldrich) and 1.6 $\mu \mathrm{M}$ EthDIII (Biotium/ Hölzel Diagnostika) and subsequently imaged on an Olympus Fluoview 1000 confocal laser scanning microscope equipped with an incubation chamber at $37^{\circ} \mathrm{C}, 5 \% \mathrm{CO}_{2}$ and $55 \%$ humidity. EthDIII ${ }^{+}$ECs were quantified with ImageJ and expressed as a percentage of all ECs.

\section{Protease activity assay}

Inhibitory effect of ADAM17 PD on ADAM17 activity was determined by a peptide-based activity assay. $50 \mathrm{nM}$ recombinant human ADAM17 catalytic domain was mixed with increasing concentrations of either TAPI-1 (\#BML-PI134; Enzo Life Sciences) or recombinant ADAM17 PD. After incubation for $10 \mathrm{~min}$ at $37^{\circ} \mathrm{C}, 5 \mu \mathrm{M}$ PEPDAB014 (BioZyme) ADAM17 substrate peptide was added. Alternatively, cells were washed once with PBS and incubated for $30 \mathrm{~min}$ with the indicated inhibitors at $37^{\circ} \mathrm{C}$ and $5 \% \mathrm{CO}_{2}$ before the addition of the indicated stimuli and $5 \mu \mathrm{M}$ PEPDAB014 substrate peptide. Subsequently, the change in fluorescence intensity was recorded every $30 \mathrm{~s}$ for $18 \mathrm{~min}$. The initial linear slope was determined by linear regression and plotted against the inhibitor concentrations. IC $_{50}$ values were calculated by four-parameter nonlinear curve fitting using GraphPad Prism software.

\section{Data analysis and statistics}

Data were checked for consistency and normality by using normal probability plots and Kolmogorov-Smirnov tests. Independent Student's $t$ test with and without the assumption of variance homogeneity were used, and Levene's test was used to test for variance homogeneity. Bootstrap $t$ tests with and without assumption of variance homogeneity based on 5,000 Monte Carlo simulations were also used. In case of log-normal or $\gamma$-distributed data, semiparametric generalized linear models based on log-normal and $\gamma$-distributions were used. MannWhitney $U$ test was used to compare two independent groups nonparametrically. ANOVA and Welch's ANOVA were used to test for fixed factors, and a random-effects model was also used. Generalized estimating equation models with various distributions (normal, log-normal, $\gamma$, and Tweedie) were used for continuously distributed variables, and corresponding least significant difference tests were used for pairwise comparisons. The robust estimator for the covariance matrix was used.

When using linear regression analysis, the initial linear slope was determined by and plotted against the inhibitor concentrations. $\mathrm{IC}_{50}$ values were calculated by four-parameter nonlinear curve fitting. All reported tests were two sided, and two-sided $\mathrm{P}<$ 0.05 was considered statistically significant. All statistical analyses in this article were performed by use of NCSS 10 software (NCSS, 
LLC), Statistica 13 (Hill and Lewicki, 2006), SPSS version 27 for Windows (IBM Corporation), RStudio (RStudio Team, 2020), Mathematica version 12 (Wolfram Research), and GraphPad Prism 8.0.0 for Windows (GraphPad Software). In case of experimental reproduction and replication, details of statistical analyses for the computation of an a priori power analysis are given as means, sample sizes, and SEs.

\section{Online supplemental material}

Fig. S1 shows that host ADAM17 promotes metastasis. Fig. S2 shows genetic deficiency of ADAM17 and TNFR1 in human and murine ECs. Fig. S3 shows CRISPR/Cas9-mediated generation of TNF-deficient murine TCs. Fig. S4 shows that the TNFR1 ectodomain is released via ADAM17-mediated proteolysis. Fig. S5 shows an analysis of $\mathrm{IC}_{50}$ of TAPI-1 and ADAM17 PD using recombinant catalytic domain of ADAM17 and a quenched fluorogenic TGF- $\alpha$-based substrate peptide. Table S1 lists the reagents and resources used in this study. Table S2 lists the antibodies for immunoblotting, immunofluorescence, FACS, and immunoprecipitation used in this study. Table S3 lists siRNAs used in this study. Table S4 lists sgRNAs used in this study. Table S5 lists pulse settings during Neon electroporation.

\section{Acknowledgments}

We thank Konrad Aden and Bimba Hoyer (University Medical Center Schleswig-Holstein) for the provision of etanercept. We thank Silke Horn and Fabian Neumann for excellent technical assistance. We are grateful to the members of the Victor-Hensen animal facility at the Christian-Albrechts-University Kiel. We thank Frank D. Böhmer for fruitful discussions and critical reading of the manuscript. We are grateful to Arne Bathke (Department of Mathematics, Paris-Lodron-University Salzburg) for discussions on statistical issues.

This work was supported by the Deutsche Forschungsgemeinschaft grants SFB841 (project C1 to D. Schmidt-Arras and S. Rose-John, C3 to E. Galun) and SFB877 (project number 125440785, project A1 to S. Rose-John, projects A3 and Z3 to P. Saftig, projects A9 and A15 to C. Becker-Pauly, and project B2 to D. Adam), the Australian Technology Network/Deutscher Akademischer Austauschdienst (project-based personnel exchange program to D. Schmidt-Arras, 57315783), the Medical Faculty of the Christian-Albrechts-University Kiel (to J. Bolik and D. SchmidtArras, F358901), and the Cluster of Excellence "Inflammation at Interfaces" to S. Rose-John. The Biomaterial Bank of the Comprehensive Cancer Center is a member of the biobanking network Pop-Gen 2.0 Network, Medical Faculty, ChristianAlbrechts-University Kiel, and was supported by Federal Ministry of Education and Research grant 01EY1103.

Author contributions: D. Schmidt-Arras conceived the project, supervised experimentation, performed the data analysis, and wrote the manuscript. J. Bolik, F. Krause, M. Stevanovic, M. Gandraß, and J. Fritsch performed most experiments, performed the data analysis, and contributed to the manuscript writing. I. Thomsen, S. Schacht, and E. Rieser performed the experiments. J. Bergmann, C. Röder, C. Schafmayer, and J.-H. Egberts isolated, archived, and provided human lung tissue specimens. R.
Wichert and C. Becker-Pauly produced and provided recombinant ADAM17 catalytic domain. W. Schneider-Brachert provided TNFR1 expression plasmids. R. Barikbin provided TNFR1 ${ }^{-/-}$ mice. D. Adams provided material, scientific insight, and $\mathrm{RIPK}^{-/-}$mice. P. Saftig provided PSEN-deficient mEFs. M. Voss contributed to the generation of TNF-deficient TCs. R. Lucius contributed to the tissue analysis. M. Müller and N. Schumacher performed the animal experimentation and data analysis. B. Strilic provided HMVEC-L and scientific insight and contributed to the manuscript writing. W. Hitzl performed the data analysis and statistics. A. Krüger provided LacZ-expressing TCs and scientific insight. E. Galun and S. Schacht provided scientific insight. I. Sagi generated ADAM17 PD and contributed to the data analysis. H. Walczak provided material, analyzed data, and contributed to writing the manuscript. S. Rose-John provided scientific insight, analyzed data, and contributed to manuscript writing. All authors edited and approved the manuscript.

Disclosures: I. Sagi reported a patent (no. US 10,933,122 B2) issued. D. Schmidt-Arras reported personal fees from Mestag Therapeutics Ltd. outside the submitted work. No other disclosures were reported.

Submitted: 21 May 2020

Revised: 8 June 2021

Accepted: 3 November 2021

\section{References}

Abdul Pari, A.A., M. Singhal, and H.G. Augustin. 2021. Emerging paradigms in metastasis research. J. Exp. Med. 218:e20190218. https://doi.org/10 $.1084 /$ jem.20190218

Blaydon, D.C., P. Biancheri, W.-L. Di, V. Plagnol, R.M. Cabral, M.A. Brooke, D.A. van Heel, F. Ruschendorf, M. Toynbee, A. Walne, et al. 2011. Inflammatory skin and bowel disease linked to ADAM17 deletion. N. Engl. J. Med. 365:1502-1508. https://doi.org/10.1056/NEJMoa1100721

Bonapace, L., M.-M. Coissieux, J. Wyckoff, K.D. Mertz, Z. Varga, T. Junt, and M. Bentires-Alj. 2014. Cessation of CCL2 inhibition accelerates breast cancer metastasis by promoting angiogenesis. Nature. 515:130-133. https://doi.org/10.1038/nature13862

Brakebusch, C., E.E. Varfolomeev, M. Batkin, and D. Wallach. 1994. Structural requirements for inducible shedding of the p55 tumor necrosis factor receptor. J. Biol. Chem. 269:32488-32496. https://doi.org/10.1016/S0021 -9258(18)31661-2

Brenner, D., H. Blaser, and T.W. Mak. 2015. Regulation of tumour necrosis factor signalling: live or let die. Nat. Rev. Immunol. 15:362-374. https:// doi.org/10.1038/nri3834

Cai, Z., A. Zhang, S. Choksi, W. Li, T. Li, X.-M. Zhang, and Z.-G. Liu. 2016. Activation of cell-surface proteases promotes necroptosis, inflammation and cell migration. Cell Res. 26:886-900. https://doi.org/10.1038/cr.2016.87

Chalaris, A., N. Adam, C. Sina, P. Rosenstiel, J. Lehmann-Koch, P. Schirmacher, D. Hartmann, J. Cichy, O. Gavrilova, S. Schreiber, et al. 2010. Critical role of the disintegrin metalloprotease ADAM17 for intestinal inflammation and regeneration in mice. J. Exp. Med. 207:1617-1624. https://doi.org/10.1084/jem.20092366

Chhibber-Goel, J., C. Coleman-Vaughan, V. Agrawal, N. Sawhney, E. Hickey, J.C. Powell, and J.V. McCarthy. 2016. $\gamma$-Secretase activity is required for regulated intramembrane proteolysis of tumor necrosis factor (TNF) receptor 1 and TNF-mediated pro-apoptotic signaling. J. Biol. Chem. 291: 5971-5985. https://doi.org/10.1074/jbc.M115.679076

Clausen, B.E., C. Burkhardt, W. Reith, R. Renkawitz, and I. Förster. 1999. Conditional gene targeting in macrophages and granulocytes using LysMcre mice. Transgenic Res. 8:265-277. https://doi.org/10.1023/A: 1008942828960

Fuchslocher Chico, J., M. Falk-Paulsen, A. Luzius, C. Saggau, B. Ruder, J. Bolik, D. Schmidt-Arras, A. Linkermann, C. Becker, P. Rosenstiel, et al. 2018. 
The enhanced susceptibility of ADAM-17 hypomorphic mice to DSSinduced colitis is not ameliorated by loss of RIPK3, revealing an unexpected function of ADAM-17 in necroptosis. Oncotarget. 9:12941-12958. https://doi.org/10.18632/oncotarget.24410

Grell, M., E. Douni, H. Wajant, M. Löhden, M. Clauss, B. Maxeiner, S. Georgopoulos, W. Lesslauer, G. Kollias, K. Pfizenmaier, and P. Scheurich. 1995. The transmembrane form of tumor necrosis factor is the prime activating ligand of the $80 \mathrm{kDa}$ tumor necrosis factor receptor. Cell. 83: 793-802. https://doi.org/10.1016/0092-8674(95)90192-2

Hänggi, K., L. Vasilikos, A.F. Valls, R. Yerbes, J. Knop, L.M. Spilgies, K. Rieck, T. Misra, J. Bertin, P.J. Gough, et al. 2017. RIPK1/RIPK3 promotes vascular permeability to allow TC extravasation independent of its necroptotic function. Cell Death Dis. 8:e2588. https://doi.org/10.1038/cddis .2017 .20

Hill, T., and P. Lewicki. 2006. Statistics: Methods and Applications. StatSoft, Tulsa, OK.

Horiuchi, K., T. Kimura, T. Miyamoto, H. Takaishi, Y. Okada, Y. Toyama, and C.P. Blobel. 2007. Cutting edge: TNF-alpha-converting enzyme (TACE/ ADAM17) inactivation in mouse myeloid cells prevents lethality from endotoxin shock. J. Immunol. 179:2686-2689. https://doi.org/10.4049/ jimmunol.179.5.2686

Hou, J., J. Ju, Z. Zhang, C. Zhao, Z. Li, J. Zheng, T. Sheng, H. Zhang, L. Hu, X. $\mathrm{Yu}$, et al. 2019. Discovery of potent necroptosis inhibitors targeting RIPK1 kinase activity for the treatment of inflammatory disorder and cancer metastasis. Cell Death Dis. 10:493. https://doi.org/10.1038/s41419 $-019-1735-6$

Inoue, A., J. Ishiguro, H. Kitamura, N. Arima, M. Okutani, A. Shuto, S. Higashiyama, T. Ohwada, H. Arai, K. Makide, and J. Aoki. 2012. TGFa shedding assay: an accurate and versatile method for detecting GPCR activation. Nat. Methods. 9:1021-1029. https://doi.org/10.1038/nmeth .2172

Ji, H., R. Cao, Y. Yang, Y. Zhang, H. Iwamoto, S. Lim, M. Nakamura, P. Andersson, J. Wang, Y. Sun, et al. 2014. TNFR1 mediates TNF- $\alpha$-induced tumour lymphangiogenesis and metastasis by modulating VEGF-CVEGFR3 signalling. Nat. Commun. 5:4944. https://doi.org/10.1038/ ncomms5944

Kim, S., H. Takahashi, W.-W. Lin, P. Descargues, S. Grivennikov, Y. Kim, J.-L. Luo, and M. Karin. 2009. Carcinoma-produced factors activate myeloid cells through TLR2 to stimulate metastasis. Nature. 457:102-106. https://doi.org/10.1038/nature07623

Lafont, E., P. Draber, E. Rieser, M. Reichert, S. Kupka, D. de Miguel, H. Draberova, A. von Mässenhausen, A. Bhamra, S. Henderson, et al. 2018. TBK1 and IKK $\varepsilon$ prevent TNF-induced cell death by RIPK1 phosphorylation. Nat. Cell Biol. 20:1389-1399. https://doi.org/10.1038/s41556-018 $-0229-6$

Martin, O.A., R.L. Anderson, K. Narayan, and M.P. MacManus. 2017. Does the mobilization of circulating tumour cells during cancer therapy cause metastasis? Nat. Rev. Clin. Oncol. 14:32-44. https://doi.org/10.1038/ nrclinonc.2016.128

Moreland, L.W., S.W. Baumgartner, M.H. Schiff, E.A. Tindall, R.M. Fleischmann, A.L. Weaver, R.E. Ettlinger, S. Cohen, W.J. Koopman, K. Mohler, et al. 1997. Treatment of rheumatoid arthritis with a recombinant human tumor necrosis factor receptor (p75)-Fc fusion protein. $N$. Engl. J. Med. 337:141-147. https://doi.org/10.1056/NEJM199707173370301

Murphy, G. 2008. The ADAMs: signalling scissors in the tumour microenvironment. Nat. Rev. Cancer. 8:929-941. https://doi.org/10.1038/ nrc2 459

Napetschnig, J., and H. Wu. 2013. Molecular basis of NF-кB signaling. Annu. Rev. Biophys. 42:443-468. https://doi.org/10.1146/annurev-biophys $-083012-130338$

Newton, K., X. Sun, and V.M. Dixit. 2004. Kinase RIP3 is dispensable for normal NF-kappa Bs, signaling by the B-cell and T-cell receptors, tumor necrosis factor receptor 1 , and Toll-like receptors 2 and 4 . Mol. Cell Biol. 24(4):1464-1469. https://doi.org/10.1128/MCB.24.4.1464-1469.2004

Nicolaou, A., Z. Zhao, B.H. Northoff, K. Sass, A. Herbst, A. Kohlmaier, A. Chalaris, C. Wolfrum, C. Weber, S. Steffens, et al. 2017. Adam17 deficiency promotes atherosclerosis by enhanced TNFR2 signaling in mice. Arterioscler. Thromb. Vasc. Biol. 37:247-257. https://doi.org/10.1161/ ATVBAHA.116.308682

Oikawa, N., and J. Walter. 2019. Presenilins and $\gamma$-secretase in membrane proteostasis. Cells. 8:E209. https://doi.org/10.3390/cells8030209

Pan, L., T.-M. Fu, W. Zhao, L. Zhao, W. Chen, C. Qiu, W. Liu, Z. Liu, A. Piai, Q. $\mathrm{Fu}$, et al. 2019. Higher-order clustering of the transmembrane anchor of DR5 drives signaling. Cell. 176:1477-1489.e14. https://doi.org/10.1016/j .cell.2019.02.001
Patel, S., J.D. Webster, E. Varfolomeev, Y.C. Kwon, J.H. Cheng, J. Zhang, D.L. Dugger, K.E. Wickliffe, A. Maltzman, S. Sujatha-Bhaskar, et al. 2020. RIP1 inhibition blocks inflammatory diseases but not tumor growth or metastases. Cell Death Differ. 27:161-175. https://doi.org/10.1038/s41418 -019-0347-0

Peltzer, N., and H. Walczak. 2019. Cell death and inflammation - a vital but dangerous liaison. Trends Immunol. 40:387-402. https://doi.org/10 $.1016 /$ j.it.2019.03.006

Peltzer, N., E. Rieser, L. Taraborrelli, P. Draber, M. Darding, B. Pernaute, Y. Shimizu, A. Sarr, H. Draberova, A. Montinaro, et al. 2014. HOIP deficiency causes embryonic lethality by aberrant TNFR1-mediated endothelial cell death. Cell Rep. 9(1):153-165. https://doi.org/10.1016/j.celrep .2014.08.066

Peschon, J.J., J.L. Slack, P. Reddy, K.L. Stocking, S.W. Sunnarborg, D.C. Lee, W.E. Russell, B.J. Castner, R.S. Johnson, J.N. Fitzner, et al. 1998. An essential role for ectodomain shedding in mammalian development. Science. 282:1281-1284. https://doi.org/10.1126/science.282.5392.1281

Pfeffer, K., T. Matsuyama, T.M. Kündig, A. Wakeham, K. Kishihara, A. Shahinian, K. Wiegmann, P.S. Ohashi, M. Krönke, and T.W. Mak. 1993. Mice deficient for the $55 \mathrm{kd}$ tumor necrosis factor receptor are resistant to endotoxic shock, yet succumb to L. monocytogenes infection. Cell. 73: 457-467. https://doi.org/10.1016/0092-8674(93)90134-C

Reiss, K., and P. Saftig. 2009. The "a disintegrin and metalloprotease" (ADAM) family of sheddases: physiological and cellular functions. Semin. Cell Dev. Biol. 20:126-137. https://doi.org/10.1016/j.semcdb.2008 .11 .002

Reymond, N., B.B. d'Água, and A.J. Ridley. 2013. Crossing the endothelial barrier during metastasis. Nat. Rev. Cancer. 13:858-870. https://doi.org/ $10.1038 / \mathrm{nrc} 3628$

Riethmueller, S., J.C. Ehlers, J. Lokau, S. Düsterhöft, K. Knittler, G. Dombrowsky, J. Grötzinger, B. Rabe, S. Rose-John, and C. Garbers. 2016. Cleavage Site Localization Differentially Controls Interleukin-6 Receptor Proteolysis by ADAM10 and ADAM17. Sci. Rep. 6:25550. https://doi .org/10.1038/srep25550

RStudio Team. 2020. RStudio: Integrated Development for R. http://www. rstudio.com (accessed January 9, 2020).

Scheller, J., A. Chalaris, C. Garbers, and S. Rose-John. 2011. ADAM17: a molecular switch to control inflammation and tissue regeneration. Trends Immunol. 32:380-387. https://doi.org/10.1016/j.it.2011.05.005

Schmidt, S., N. Schumacher, J. Schwarz, S. Tangermann, L. Kenner, M. Schlederer, M. Sibilia, M. Linder, A. Altendorf-Hofmann, T. Knösel, et al. 2018. ADAM17 is required for EGF-R-induced intestinal tumors via IL-6 trans-signaling. J. Exp. Med. 215:1205-1225. https://doi.org/10 $.1084 /$ jem. 20171696

Schumacher, D., B. Strilic, K.K. Sivaraj, N. Wettschureck, and S. Offermanns. 2013. Platelet-derived nucleotides promote tumor-cell transendothelial migration and metastasis via P2Y2 receptor. Cancer Cell. 24:130-137. https://doi.org/10.1016/j.ccr.2013.05.008

Sörensen, I., R.H. Adams, and A. Gossler. 2009. DLL1-mediated Notch activation regulates endothelial identity in mouse fetal arteries. Blood. 113: 5680-5688. https://doi.org/10.1182/blood-2008-08-174508

Strilic, B., and S. Offermanns. 2017. Intravascular survival and extravasation of TCs. Cancer Cell. 32:282-293. https://doi.org/10.1016/j.ccell.2017.07 .001

Strilic, B., L. Yang, J. Albarrán-Juárez, L. Wachsmuth, K. Han, U.C. Müller, M. Pasparakis, and S. Offermanns. 2016. Tumour-cell-induced endothelial cell necroptosis via death receptor 6 promotes metastasis. Nature. 536: 215-218. https://doi.org/10.1038/nature19076

Sundaram, B., K. Behnke, A. Belancic, M.A. Al-Salihi, Y. Thabet, R. Polz, R. Pellegrino, Y. Zhuang, P.V. Shinde, H.C. Xu, et al. 2019. iRhom2 inhibits bile duct obstruction-induced liver fibrosis. Sci. Signal. 12:eaax1194. https://doi.org/10.1126/scisignal.aax1194

Tournoy, J., X. Bossuyt, A. Snellinx, M. Regent, M. Garmyn, L. Serneels, P. Saftig, K. Craessaerts, B. De Strooper, and D. Hartmann. 2004. Partial loss of presenilins causes seborrheic keratosis and autoimmune disease in mice. Hum. Mol. Genet. 13(13):1321-1331. https://doi.org/10.1093/hmg/ ddh151

Vanamee, É.S., and D.L. Faustman. 2018. Structural principles of tumor necrosis factor superfamily signaling. Sci. Signal. 11:eaao4910. https://doi .org/10.1126/scisignal.aao4910

Vanamee, É.S., and D.L. Faustman. 2020. On the TRAIL of better therapies: understanding TNFRSF structure-function. Cells. 9:E764. https://doi .org/10.3390/cells9030764

Wolf, M.J., A. Hoos, J. Bauer, S. Boettcher, M. Knust, A. Weber, N. Simonavicius, C. Schneider, M. Lang, M. Stürzl, et al. 2012. Endothelial CCR2 
signaling induced by colon carcinoma cells enables extravasation via the JAK2-Stat5 and p38MAPK pathway. Cancer Cell. 22:91-105. https:// doi.org/10.1016/j.ccr.2012.05.023

Wong, E., T. Maretzky, Y. Peleg, C.P. Blobel, and I. Sagi. 2015. The functional maturation of a disintegrin and metalloproteinase (ADAM) 9, 10, and 17 requires processing at a newly identified proprotein convertase $(\mathrm{PC})$ cleavage site. J. Biol. Chem. 290:12135-12146. https://doi.org/10.1074/jbc .M114.624072

Wong, E., T. Cohen, E. Romi, M. Levin, Y. Peleg, U. Arad, A. Yaron, M.E. Milla, and I. Sagi. 2016. Harnessing the natural inhibitory domain to control
TNFa converting enzyme (TACE) activity in vivo. Sci. Rep. 6:35598. https://doi.org/10.1038/srep35598

Xu, P., J. Liu, M. Sakaki-Yumoto, and R. Derynck. 2012. TACE activation by MAPK-mediated regulation of cell surface dimerization and TIMP3 association. Sci. Signal. 5:ra34. https://doi.org/10.1126/scisignal .2002689

Yang, L., S. Joseph, T. Sun, J. Hoffmann, S. Thevissen, S. Offermanns, and B. Strilic. 2019. TAK1 regulates endothelial cell necroptosis and tumor metastasis. Cell Death Differ. 26:1987-1997. https://doi.org/10.1038/ s41418-018-0271-8 


\section{Supplemental material}


A

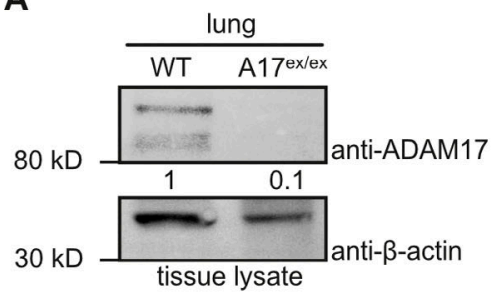

B

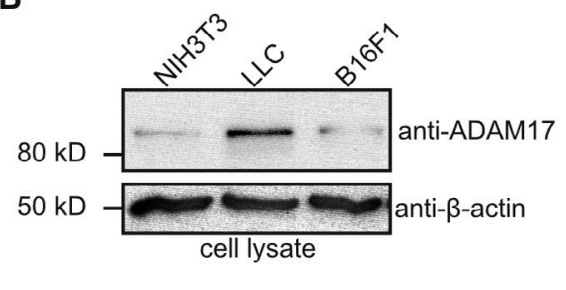

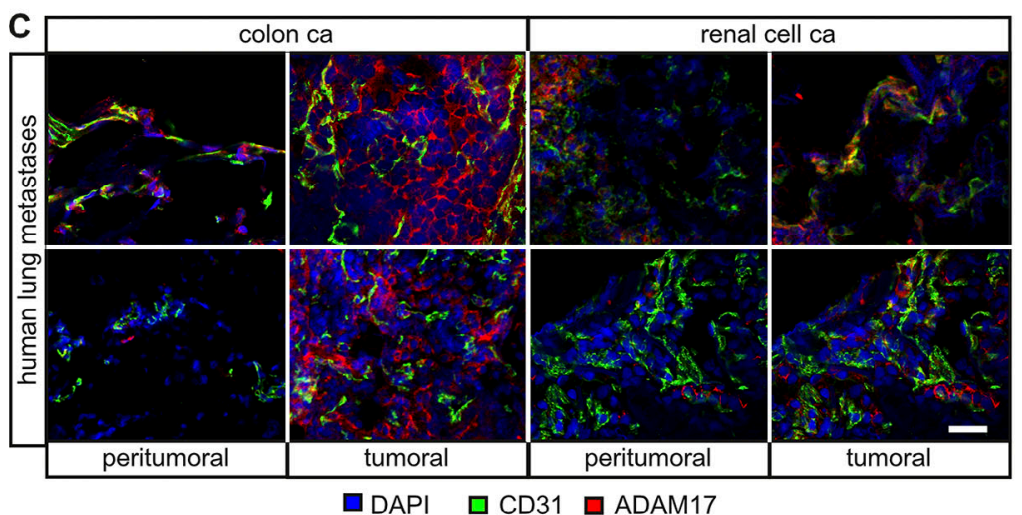

$\square$ DAPI $\square$ CD31 $\square$ ADAM17
D

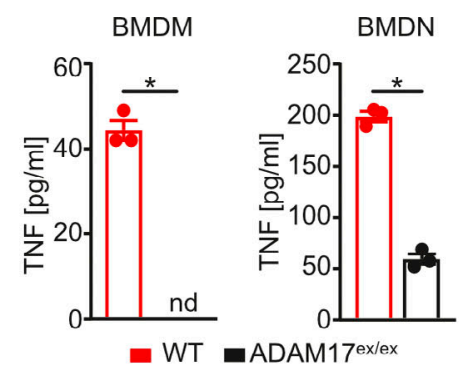

E

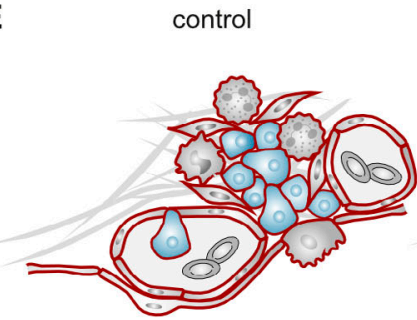

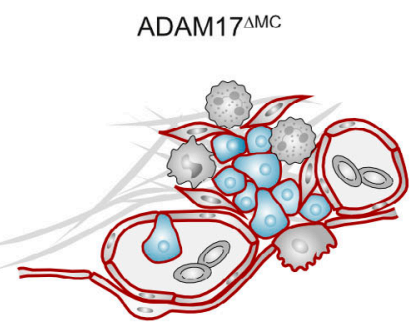

$\mathbf{F}$

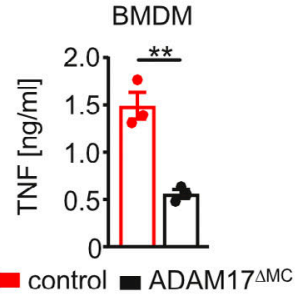

G

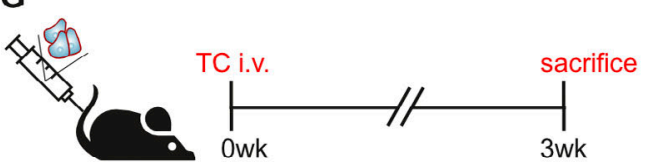

H
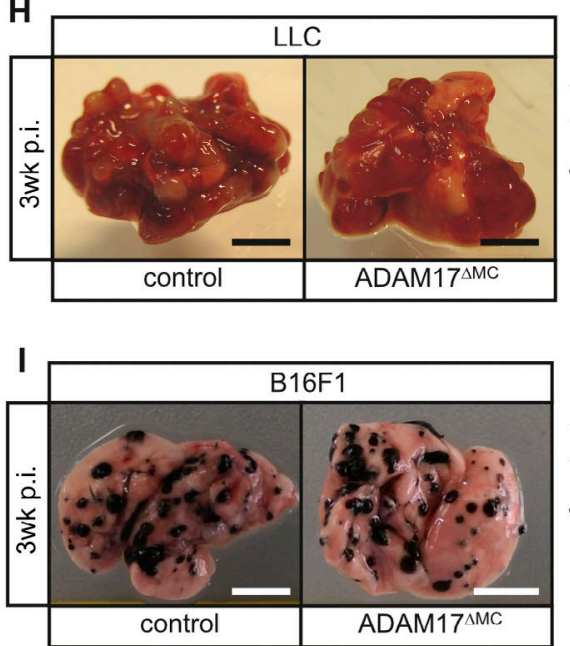


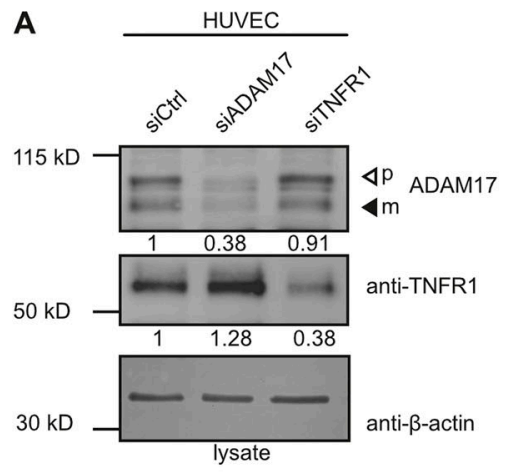

B

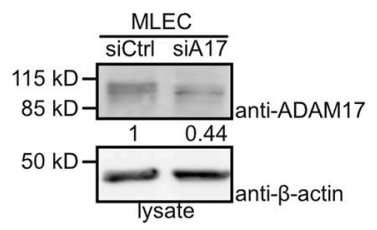

C

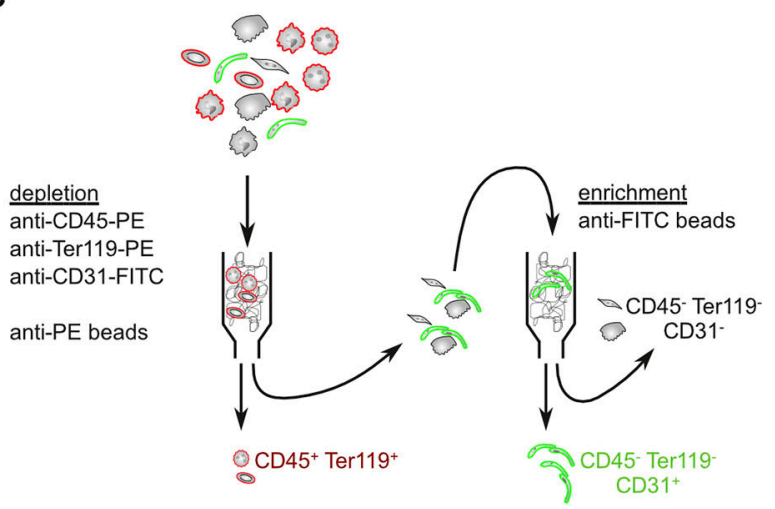

D
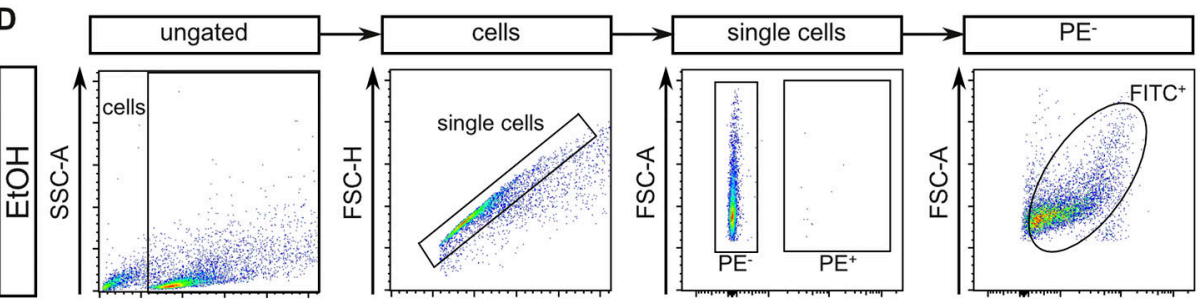

PE-FITC ${ }^{+}$
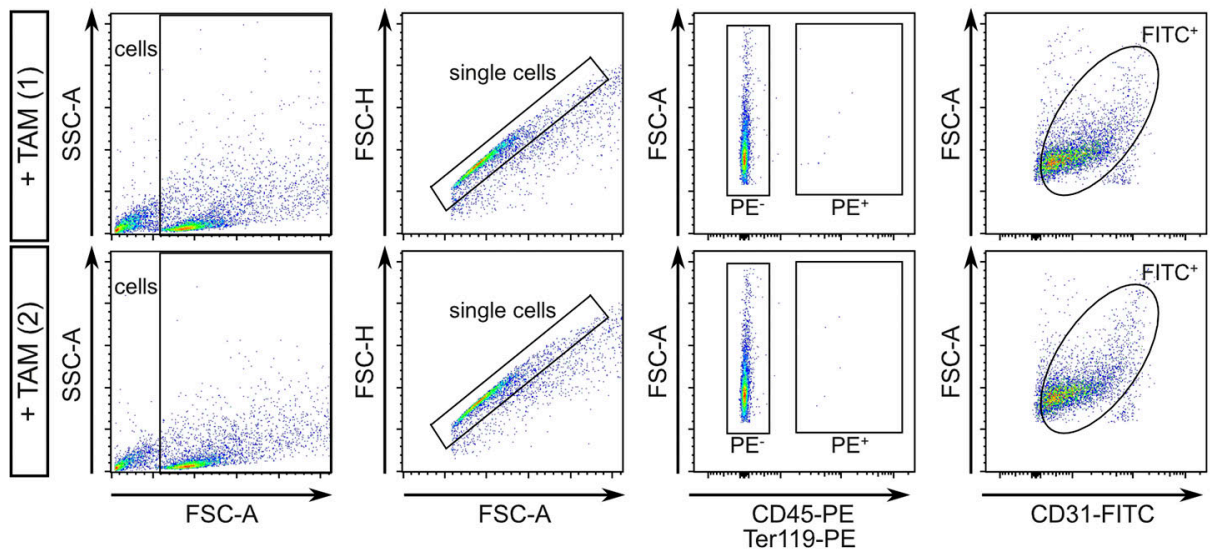

$61.4 \%$ of ungated

$79.8 \%$ of cells
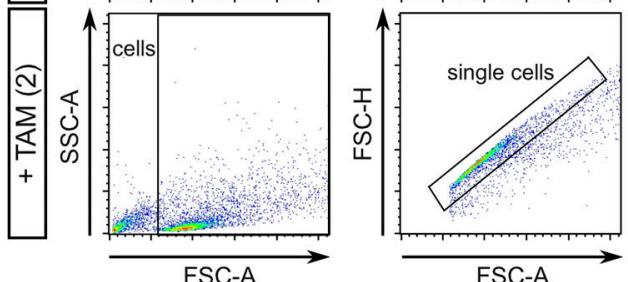

$49.4 \%$ of ungated

$77.9 \%$ of cells

E
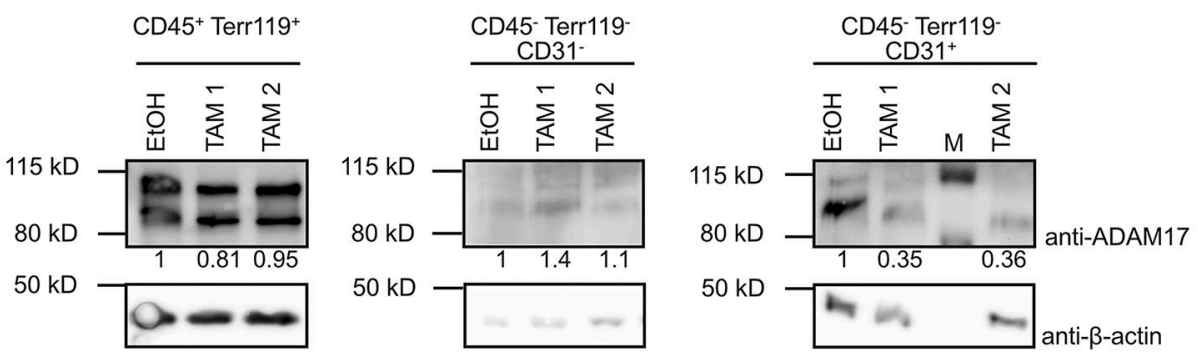

Figure S2. Genetic deficiency of ADAM17 and TNFR1 in human and murine ECs. (A) Immunoblot analysis of HUVECs with siRNA-mediated suppression of ADAM17 or TNFR1, respectively. (B) Immunoblot analysis of MLECs with siRNA-mediated suppression of ADAM17. (C) Strategy for MACS-based isolation of murine lung ECs. (D) Representative FACS plots after different purification steps during murine lung EC isolation. (E) ADAM17 expression of the indicated cell populations was assessed by immunoblot analysis and indicates specific ADAM17 deficiency in lung ECs in tamoxifen (TAM)-treated Cdh5-CreERT2:: ADAM17flox/flox mice. Ctrl, control; SSC-A, side scatter area; FSC-A, forward scatter area; FSC-H, forward scatter height. 
A

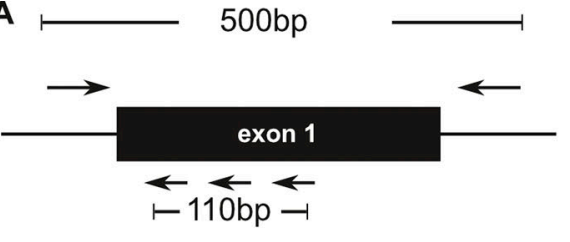

B

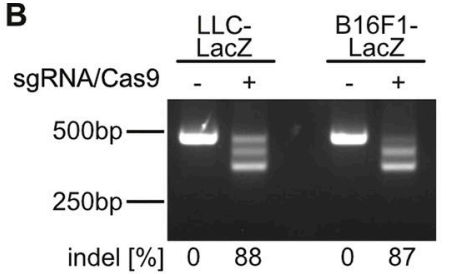

C

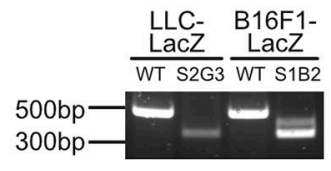

D

Tnf exon 1

Tnf CDS

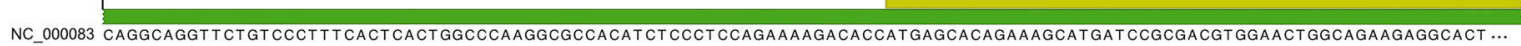
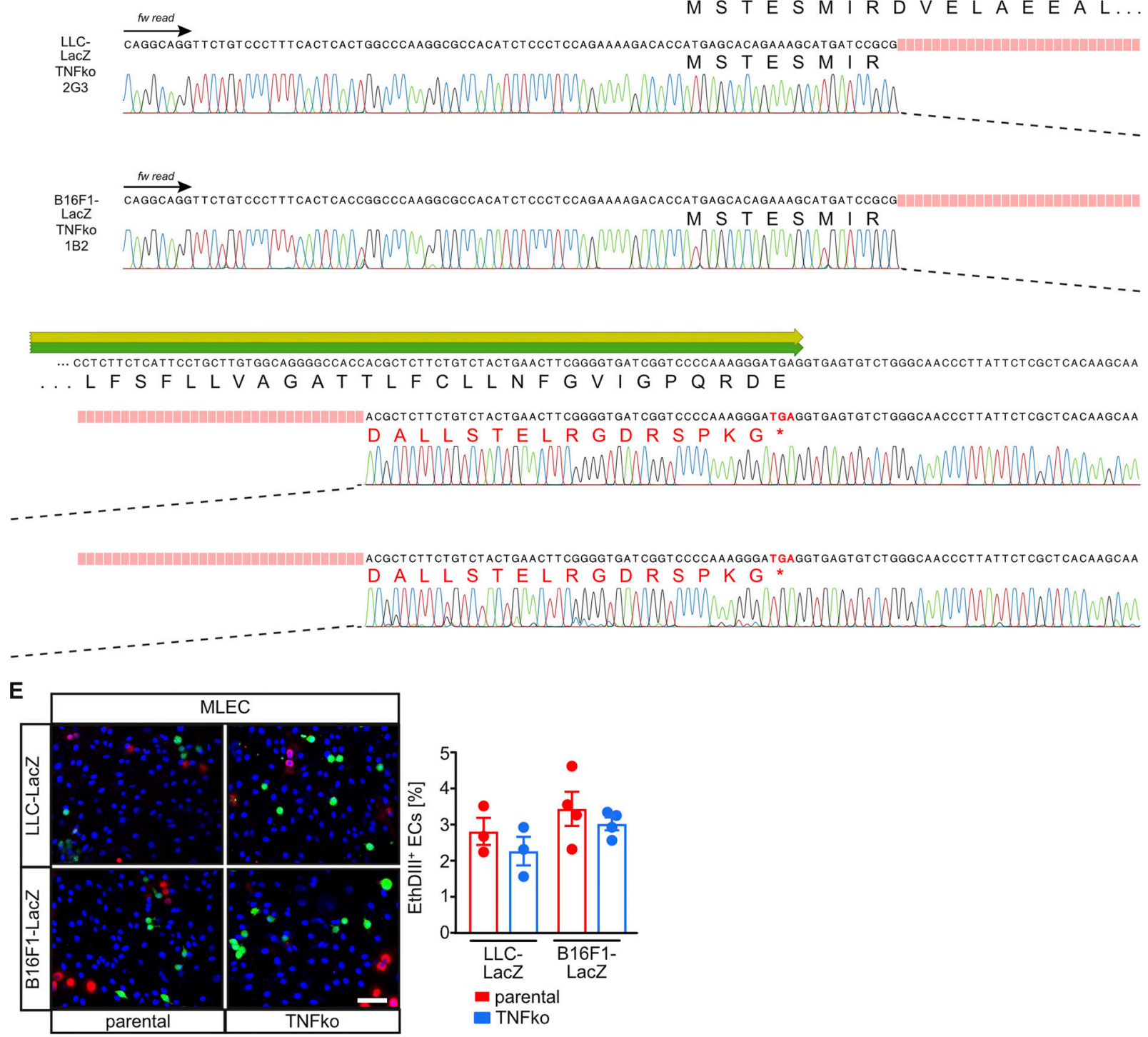

口EthDIII पH33342 Dtumor cell

Figure S3. CRISPR/Cas9-mediated generation of TNF-deficient murine TCs. (A) Targeting and genotyping strategy. Exon 1 of murine Tnf is shown. Arrows below indicate targeting area of sgRNAs. Combination of cleavage events can result in the deletion of a 110-bp fragment. Arrows above indicate PCR primers resulting in a 500-bp PCR product of unmodified Tnf. (B) PCR-based genotyping of pool of targeted murine TCs indicates 88\% (LLC-LacZ) and 87\% (B16F1-LacZ) insertion/deletion (indel) formation. (C) PCR-based genotyping of single-cell clones used in this study demonstrates deletion of a 110-bp fragment within Tnf. (D) Sanger sequencing of $\operatorname{Tnf}$ exon 1 confirms 110-bp deletion, resulting in amino acid deletion, a frameshift, and the appearance of a premature stop codon after a total of 24 amino acids in targeted TCs. (E) TNF-deficient LacZ-expressing B16F1 TCs were labeled with CSFE and cocultured on murine MLECs. Cells with impaired membrane integrity were determined after $6 \mathrm{~h}$ by EthDIII uptake. Shown are representative images of three to four independent experiments with three technical replicates and three to four images per replicate. Scale bar indicates $50 \mu \mathrm{m}$; unpaired one-tailed Mann-Whitney $U$ test. Data represent mean $\pm \mathrm{SEM}$. fw, forward. 
A
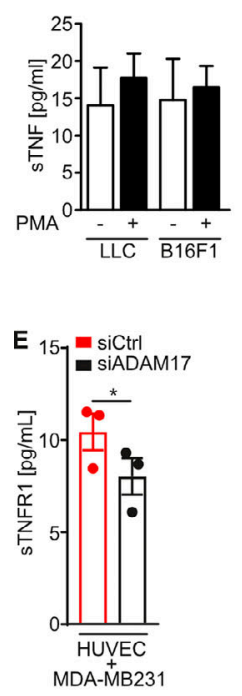

G

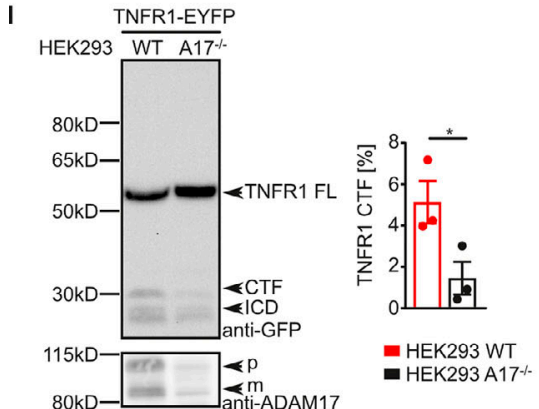

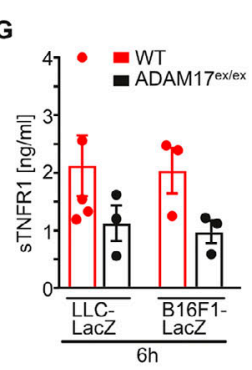

MDA-MB23
B
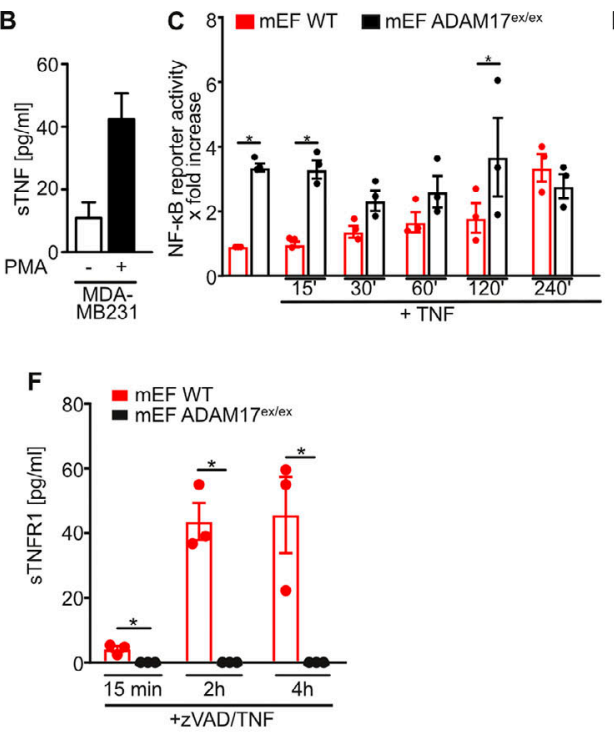

D
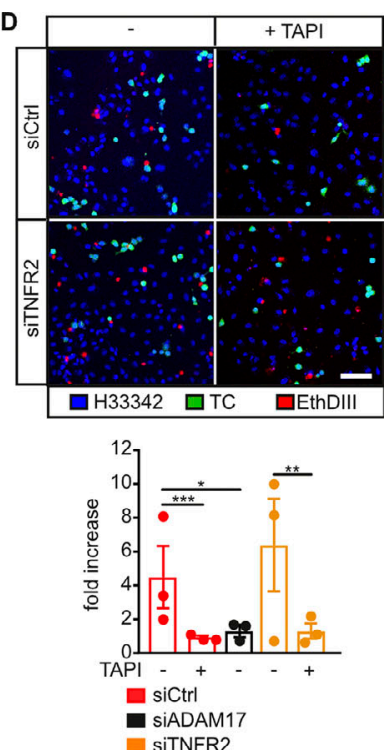

H

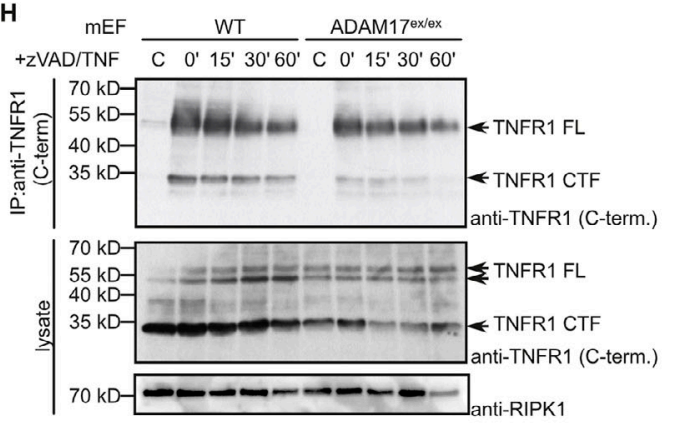

J

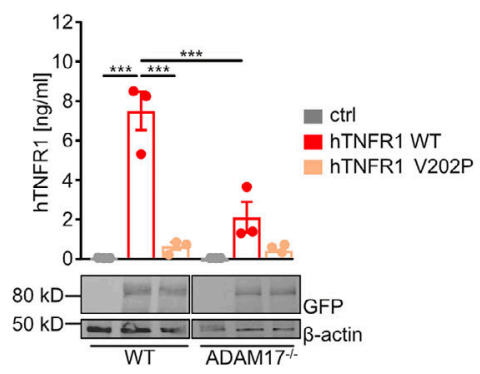

Figure S4. TNFR1 ectodomain is released via ADAM17-mediated proteolysis. (A and B) The indicated TCs were mock treated or stimulated with $500 \mathrm{nM}$ PMA, and soluble TNF (sTNF)- $a$ in the supernatant was determined by ELISA. Shown is the quantification of three independent experiments. Unpaired onetailed Mann-Whitney U test. (C) WT and ADAM17ex/ex mEFs were transfected with an NF-kB luciferase reporter plasmid, stimulated with $200 \mathrm{ng} / \mathrm{ml}$ TNF-a for the indicated time points, and luciferase activity was determined according to standard procedures. *, $\mathrm{P}<0.05$ by one-way ANOVA on ranks with Bonferroni's post hoc test. (D) HUVECs with indicated siRNA-mediated knockdown were cocultured with CFSE-labeled MDA-MB231 TCs in the absence or presence of 250 nM TAPI-1. Cells with impaired membrane integrity were determined after $6 \mathrm{~h}$ by EthDIII uptake. Shown are representative images of three independent experiments with three technical replicates per experiment and three to four images per replicate analyzed. Scale bar indicates $50 \mu \mathrm{m} .{ }^{*}, \mathrm{P}<0.05 ;{ }^{* *}, \mathrm{P}<0.01$; ***, $\mathrm{P}<0.001$ by one-way ANOVA on ranks with Dunn's post hoc test. (E) HUVECs with indicated siRNA-mediated knockdown were cocultured with MDAMB231 cells, and sTNFR1 in the supernatant was determined by ELISA. The quantification of three independent experiments is shown. ${ }^{*}, P<0.05$ by unpaired two-tailed Student's $t$ test. (F) WT or ADAM17 ${ }^{\mathrm{ex} / \mathrm{ex}} \mathrm{mEFs}$ were stimulated for the indicated time points with $100 \mu \mathrm{M}$ zVAD and $50 \mathrm{ng} / \mathrm{ml}$ TNF-a. Release of sTNFR1 was assessed by ELISA. The quantification of three independent experiments is shown. ${ }^{*}, \mathrm{P}<0.05$ by one-way ANOVA on ranks with Bonferroni's post hoc test. (G) LacZ-expressing LLC TCs were i.v. injected into the indicated mouse strains. $6 \mathrm{~h}$ later, mice were sacrificed, and plasma levels of sTNFR1 were determined by ELISA. $n=3-5$ mice/group; unpaired two-tailed Mann-Whitney $U$ test. (H) WT and ADAM17ex/ex mEFs were stimulated with zVAD/TNF-a for the indicated time points and subjected to cell lysis. TNFR1 was isolated by immunoprecipitation (IP) and subsequently analyzed by SDS-PAGE and immunoblotting using the indicated antibodies. (I) TNFR1-EYFP was overexpressed in parental (WT) or ADAM17-deficient HEK293T cells (A17-/-), and TNFR1 proteolysis was assessed by SDS-PAGE and immunoblotting using the indicated antibodies. Shown is one representative blot and the quantification of the C-terminal fragment (CTF) formation of three independent experiments. *, P $<0.05$ by unpaired two-tailed Mann-Whitney U test. (J) WT HEK293T cells or HEK293T cells with CRISPR/Cas9-mediated ADAM17-/- were transfected with the indicated TNFR1 variants, and the generation of sTNFR1 was determined by ELISA. ${ }^{* * *}, \mathrm{P}<0.001$ by one-way ANOVA with Tukey's post hoc test. Data represent mean \pm SEM. C/Ctrl, control; C-term., C-terminus; FL, full length; ICD, intracellular domain. 
A

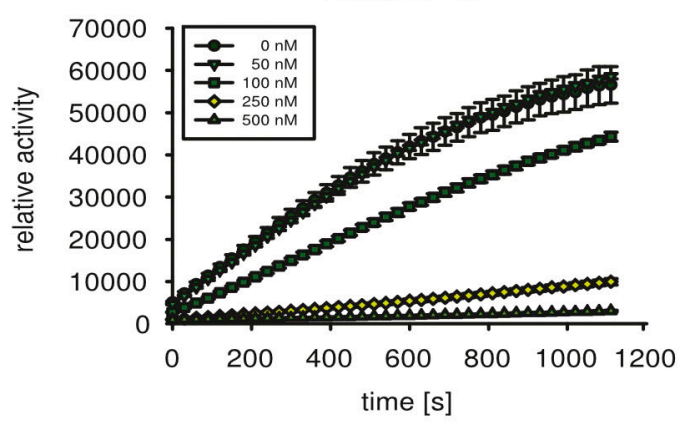

C
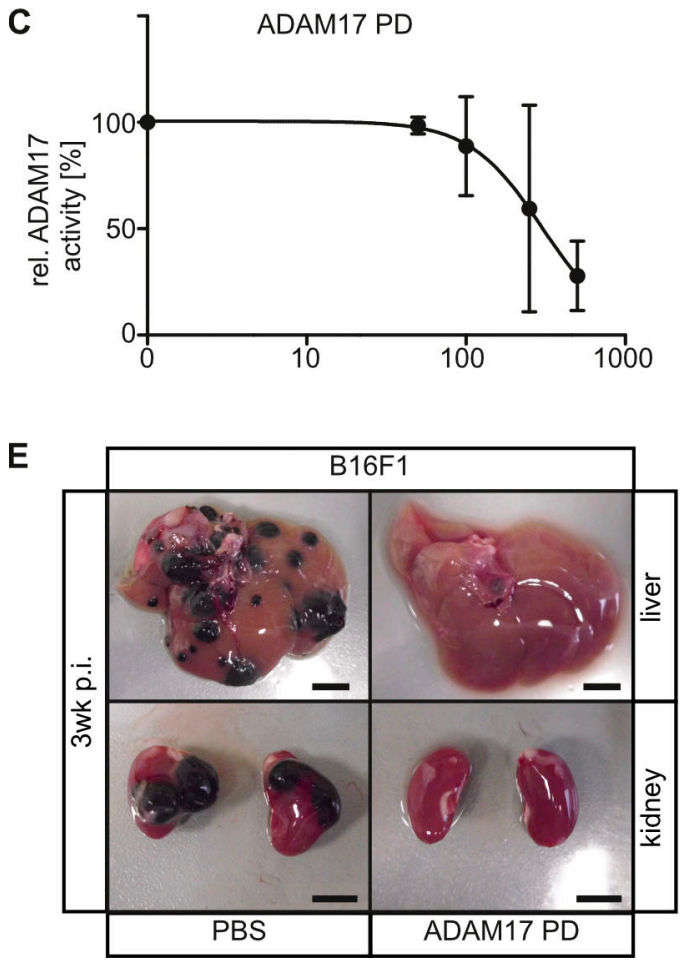

B
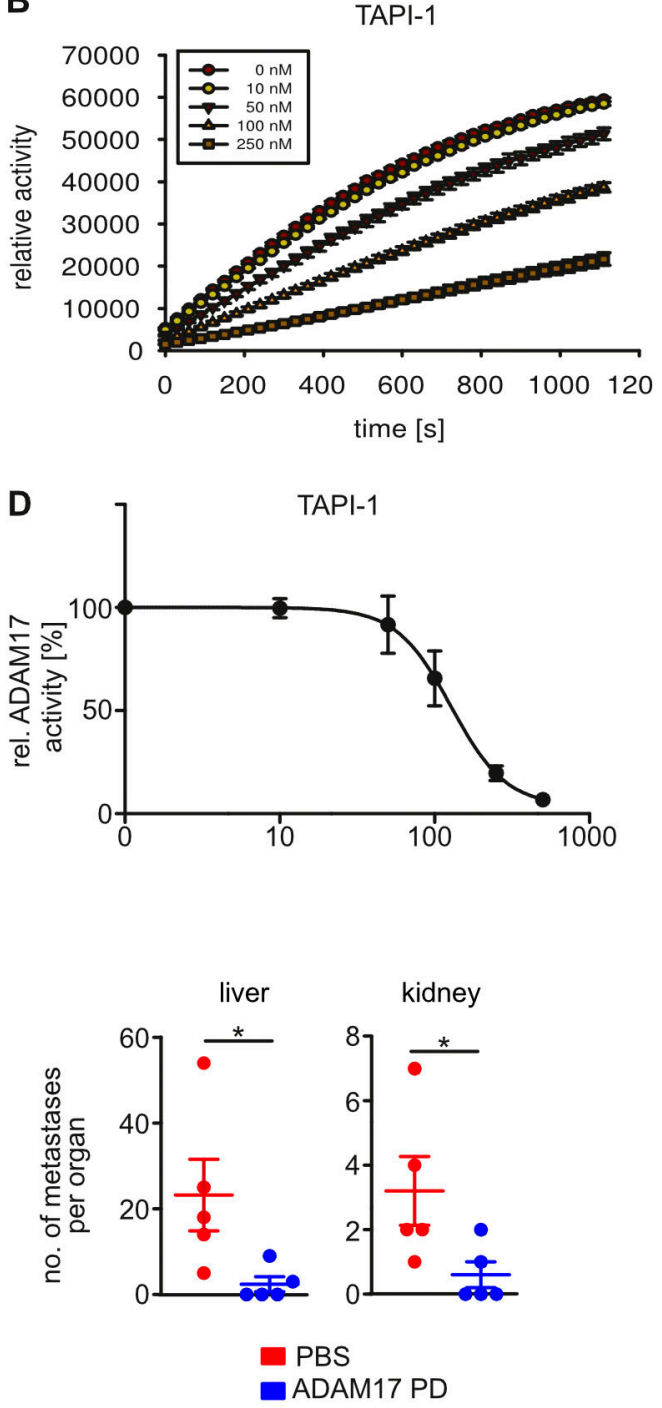

Figure S5. IC 50 of TAPI-1 and ADAM17 PD were analyzed using recombinant catalytic domain of ADAM17 and a quenched fluorogenic TGF-a-based substrate peptide. (A-D) The relative velocity determined by linear regression and $I C_{50}$ values calculated using four-parameter logistic curve fitting. One representative experiment ( $A$ and $B$ ) and the quantification of three independent experiments are shown. (E) WT animals were i.v. injected with $1 \mathrm{mg} / \mathrm{kg}$ BW ADAM17 PD 10 min before i.v. injection with $5 \times 10^{5}$ B16F1 TCs, and $21 \mathrm{~d}$ after injection, liver and kidney metastases were determined. Liver and kidney images $21 \mathrm{~d}$ after TC injection are shown. Scale bars indicate $5 \mathrm{~mm} . n=4-5$ mice/group. ${ }^{*}, \mathrm{P}<0.05$ by unpaired two-tailed Student's $t$ test. Data represent mean \pm SEM. p.i., postinjection; rel., relative.

Provided online are five tables as separate Word files. Table S1 lists the reagents and resources used in this study. Table S2 lists the antibodies for immunoblotting, immunofluorescence, FACS, and immunoprecipitation used in this study. Table S3 lists siRNAs used in this study. Table S4 lists sgRNAs used in this study. Table S5 lists pulse settings during Neon electroporation. 